Research Paper

\title{
Effects of Chinese herbal medicines on the occurrence of diabetic retinopathy in type 2 diabetes patients and protection of ARPE-19 retina cells by inhibiting oxidative stress
}

\author{
Fuu-Jen Tsai ${ }^{1,2,3, *}$, Te-Mao $\mathrm{Li}^{1, *}$, Cheng-Hang Ko ${ }^{4, *}$, Chi-Fung Cheng ${ }^{5}$, Tsung-Jung \\ $\mathrm{Ho}^{1}$, Xiang Liu ${ }^{6}$, Hsinyi Tsang ${ }^{6}$, Ting-Hsu Lin ${ }^{2}$, Chiu-Chu Liao ${ }^{2}$, Ju-Pi Li ${ }^{1,7}$, Shao-Mei \\ Huang $^{2}$, Jung-Chun Lin ${ }^{8}$, Chih-Chien Lin ${ }^{9}$, Wen-Miin Liang ${ }^{5, *}$ and Ying-Ju Lin ${ }^{1,2, *}$ \\ ${ }^{1}$ School of Chinese Medicine, China Medical University, Taichung, Taiwan \\ ${ }^{2}$ Genetic Center, Department of Medical Research, China Medical University Hospital, Taichung, Taiwan \\ ${ }^{3}$ Department of Health and Nutrition Biotechnology, Asia University, Taichung, Taiwan \\ ${ }^{4}$ Department of Chinese Medicine, China Medical University Hospital, Taichung, Taiwan \\ ${ }^{5}$ Graduate Institute of Biostatistics, School of Public Health, China Medical University, Taichung, Taiwan \\ ${ }^{6}$ National Institute of Allergy and Infectious Diseases, National Institutes of Health, Bethesda, MD, USA \\ ${ }^{7}$ Rheumatism Research Center, China Medical University Hospital, Taichung, Taiwan \\ ${ }^{8}$ School of Medical Laboratory Science and Biotechnology, College of Medical Science and Technology, Taipei Medical \\ University, Taipei, Taiwan \\ ${ }^{9}$ Department of Cosmetic Science, Providence University, Taichung, Taiwan \\ "These authors have contributed equally to this work \\ Correspondence to: Ying-Ju Lin, email: yjlin.kath@gmail.com \\ Wen-Miin Liang, email: wmliang@mail.cmu.edu.tw \\ Keywords: type 2 diabetes, diabetic retinopathy, Chinese herbal medicine, oxidative stress, retina cells \\ Received: March 02, $2017 \quad$ Accepted: June 05, $2017 \quad$ Published: June 29, 2017 \\ Copyright: Tsai et al. This is an open-access article distributed under the terms of the Creative Commons Attribution License 3.0 \\ (CC BY 3.0), which permits unrestricted use, distribution, and reproduction in any medium, provided the original author and source \\ are credited.
}

\section{ABSTRACT}

Diabetic retinopathy is a microvascular complication of type 2 diabetes and the leading cause of acquired blindness. In Taiwan, Chinese herbal medicine (CHM) is a popular adjunctive therapy. In this study, we investigated the CHM prescription patterns and their effects. We identified 23,701 subjects with type 2 diabetes in a database, and after matching for age and gender, 6,948 patients each were assigned to $\mathrm{CHM}$ and non-CHM groups. In the female subgroups, the cumulative retinopathy probability was lower for the CHM users than that for the CHM non-users $(P<\mathbf{0 . 0 0 1}$, log-rank test). Among the top $10 \mathrm{CHMs}$, Jia-Wei-Xiao-Yao-San (JWXYS; 52.9\%), ShuJing-Huo-Xue-Tang (SJHXT; 45.1\%), and Ge-Gen-Tang (GGT; 43.7\%) were the most common herbal formulas. Yan-Hu-Suo (48.1\%), Ge-Gen (42.1\%), and Huang-Qin (HQin; 40.1\%) were the most common single herbs. CHM network analysis showed that JWXYS was the core CHM of cluster 1. JWXYS, DS, XF, and SZRT exhibited both of the reductions of $\mathrm{H}_{2} \mathrm{O}_{2}$-induced phosphorylation of p38 MAPK and p44/42 MAPK (Erk1/2) in human ARPE-19 retina cells. In cluster 2, SJHXT was the core CHM. SJHXT and NX showed both of the phosphorylation reductions. In cluster 3, GGT was the core CHM, and it reduced the phosphorylation of both MAPKs. In cluster 4, HQin was the core CHM, and it also reduced the phosphorylation of both MAPKs. Our study suggests that adjunctive CHM therapy may reduce diabetic retinopathy via antioxidant activity of the herbs and provides information on core CHM treatments for further scientific investigations or therapeutic interventions. 


\section{INTRODUCTION}

Type 2 diabetes (T2D) accounts for $90-95 \%$ of all cases of diabetes worldwide [1]. T2D patients have high levels of blood glucose and an impaired pancreatic $\beta$-cell function [2, 3]. Hyperglycemia damages several organs (e.g., blood vessels, heart, eyes, kidneys, and nerves) and causes cardiovascular and cerebrovascular diseases, retinopathy, nephropathy, neuropathy, and peripheral circulatory disorders. These complications are responsible for the morbidity and mortality of diabetic patients [4]. Diabetic retinopathy, the leading cause of acquired blindness [5], is associated with oxidative stress and inflammation $[6,7]$ and is one of the most common microvascular T2D complications.

The retina has high oxygen uptake and glucose oxidation rates and is susceptible to oxidative stress [8]. A higher level of mitochondrial superoxide has been observed when retina cells were incubated with high concentrations of glucose [9]. Superoxide is produced by glucose metabolism, and this reactive oxygen species (ROS) increases the oxidative stress; moreover, it is involved in the development of diabetic retinopathy [6, $7,10]$. T2D progression can be controlled by lifestyle changes [11] and pharmacological therapies, including hypoglycemic or antihyperglycemic, insulin-sensitizing, or insulin secretion-enhancing drugs [12-14]. However, these treatment regimens for the blood glucose control are frequently associated with side effects. Metaanalyses have shown that metformin-, sulfonylurea-, and thiazolidinedione-based therapies are associated with an increased risk of cardiovascular diseases and mortality [12-15]. Furthermore, long-term use of thiazolidinedione increases the risk of fractures, lower respiratory tract infections, and bladder cancer in T2D patients $[14,16,17]$. These findings have prompted to search for alternative and complementary therapies to improve the management of diabetes and its complications.

Chinese herbal medicine (CHM) is an important health care system in Taiwan $[18,19]$. People in Taiwan can take regular antidiabetic drugs, CHMs, or both. CHM prescription patterns have been investigated for various diseases, such as childhood asthma [20], breast cancer [21], chronic kidney disease [22], diabetes [23], endometriosis [24], primary dysmenorrhea [25], schizophrenia [26], and Sjögren's syndrome [27]. Moreover, improvements in the survival rate, hyperglycemia, and/or inflammation, attributed to CHM treatments, have been reported in T2D patients [28-32]. There is, however, limited information about the effects of CHM on the occurrence of diabetic retinopathy in T2D patients. In this study, we used a population-based database to investigate the demographic characteristics, CHM prescription patterns, and CHM effects on the occurrence of diabetic retinopathy in T2D patients in Taiwan. In addition, we evaluated the protective effects of most commonly used CHM treatments on human retina cells in a hypoxic state in in vitro experiments.

\section{RESULTS}

\section{Participants and their baseline characteristics}

A total of 89,955 patients were identified in the Taiwan National Health Insurance (NHI) Research Database (NHIRD), who were admitted for diabetes treatment during the observation period (between 2000 and 2009) (Figure 1). Among those, 12,985 individuals with type 1 diabetes and 802 individuals with diabetic retinopathy that occurred within 1 year after diabetes had been diagnosed were excluded. In total, 23,701 patients diagnosed with T2D between 2000 and 2009 were included in our study cohort (Figure 1). Among these patients, 7,213 (30.4\%) belonged to the CHM group, and $16,488(69.6 \%)$ belonged to the non-CHM group (Figure 1 and Table 1).

As shown in Table 1, there were significantly different frequency distributions in age, gender, comorbidities (chronic obstructive pulmonary disease, cerebrovascular disease, hyperlipidemia, hypertension, and myocardial infarction), medications (antihypertensive drug and statin use), income, and urbanization level between the CHM and non-CHM groups $(P<0.05)$. To minimize the bias in the estimated effects (i.e., group difference), these two groups were age- and gender-matched at a 1:1 ratio (Table 1), and we found significantly different frequency distributions for hyperlipidemia, income, and urbanization level $(P<0.05)$. The CHM group was characterized by more cases of hyperlipidemia, a higher income, and a higher level of urbanization.

\section{Effect of CHM on the occurrence of diabetic retinopathy among type 2 diabetes patients}

With regard to the effect of CHM on the occurrence of diabetic retinopathy among the T2D patients, the CHM use tended to be associated with a reduced hazard ratio compared with that among the CHM non-users (Table 2; overall hazard ratio: $0.88 ; 95 \%$ confidence interval: 0.70 $1.10 ; P=0.244)$. The same trend was also found when the subjects were stratified into male and female subgroups (Table 2). In particular, this subgroup analysis showed that the use of CHM was associated with a protective effect in the female subgroup (hazard ratio: $0.56 ; 95 \%$ confidence interval: $0.36-0.86 ; P=0.008$ ).

The cumulative probability of diabetic retinopathy in the female subgroups with T2D (according to the CHM use) is shown in Figure 2. In the female subgroups, the cumulative probability of diabetic retinopathy was lower among the CHM users than that among the CHM nonusers $(P<0.001, \log$-rank test $)$. 


\section{Most commonly used CHM products and their effects on $\mathrm{H}_{2} \mathrm{O}_{2}$-induced oxidative stress in human ARPE-19 retina cells}

The top 10 Chinese herbal formulations and single herbs used by the female subgroup are listed in Table 3, along with their compositions. The follow-up person-years were calculated as the interval between the T2D diagnosis and the end of the study. Based on the percentage of users, Jia-Wei-Xiao-Yao-San (JWXYS; 52.9\%) was the most commonly prescribed herbal formula, followed by Shu-Jing-Huo-Xue-Tang (SJHXT; 45.1\%), Ge-GenTang (GGT; 43.7\%), Shao-Yao-Gan-Cao-Tang (SYGCT; 38.7\%), Chuan-Xiong-Cha-Tiao-San (CXCTS; 38.0\%), Yin-Qiao-San (YQS; 35.4\%), Xue-Fu-Zhu-Yu-Tang (XFZYT; 34.6\%), Ma-Xing-Shi-Gan-Tang (MXSGT; 33.8\%), Liu-Wei-Di-Huang-Wan (LWDHW; 33.3\%), and Suan-Zao-Ren-Tang (SZRT; 30.9\%).
Of the 10 most common single herbs, Yan-Hu-Suo (YHS; 48.1\%) was most frequently prescribed, followed by Ge-Gen (GG; 42.1\%), Huang-Qin (HQin; 40.1\%), Dan-Shen (DS; 39.4\%), Jie-Geng (JG; 38.3\%), Bei-Mu (BM; 37.0\%), Tian-Hua-Fen (THF; 36.1\%), Niu-Xi (NX; $31.9 \%$ ), Xiang-Fu (XF; 31.8\%), and Huang-Qi (HQ; $31.6 \%)$.

It is possible that the loss of vision caused by diabetic retinopathy is associated with oxidative damage inflicted on retinal pigment epithelial cells [8, 33]. Studies have shown that $\mathrm{H}_{2} \mathrm{O}_{2}$-induced oxidative stress increased p38 mitogen-activated protein kinase (MAPK) and extracellular signal-regulated kinase (ERK) phosphorylation in human retina cells $[34,35]$. Therefore, to explore the potential signaling pathways involved in the protective $\mathrm{CHM}$ effects against $\mathrm{H}_{2} \mathrm{O}_{2}$-induced damage, we examined the phosphorylation status of p38 MAPK and p44/42 MAPKs (ERK1/2) in retina cells.

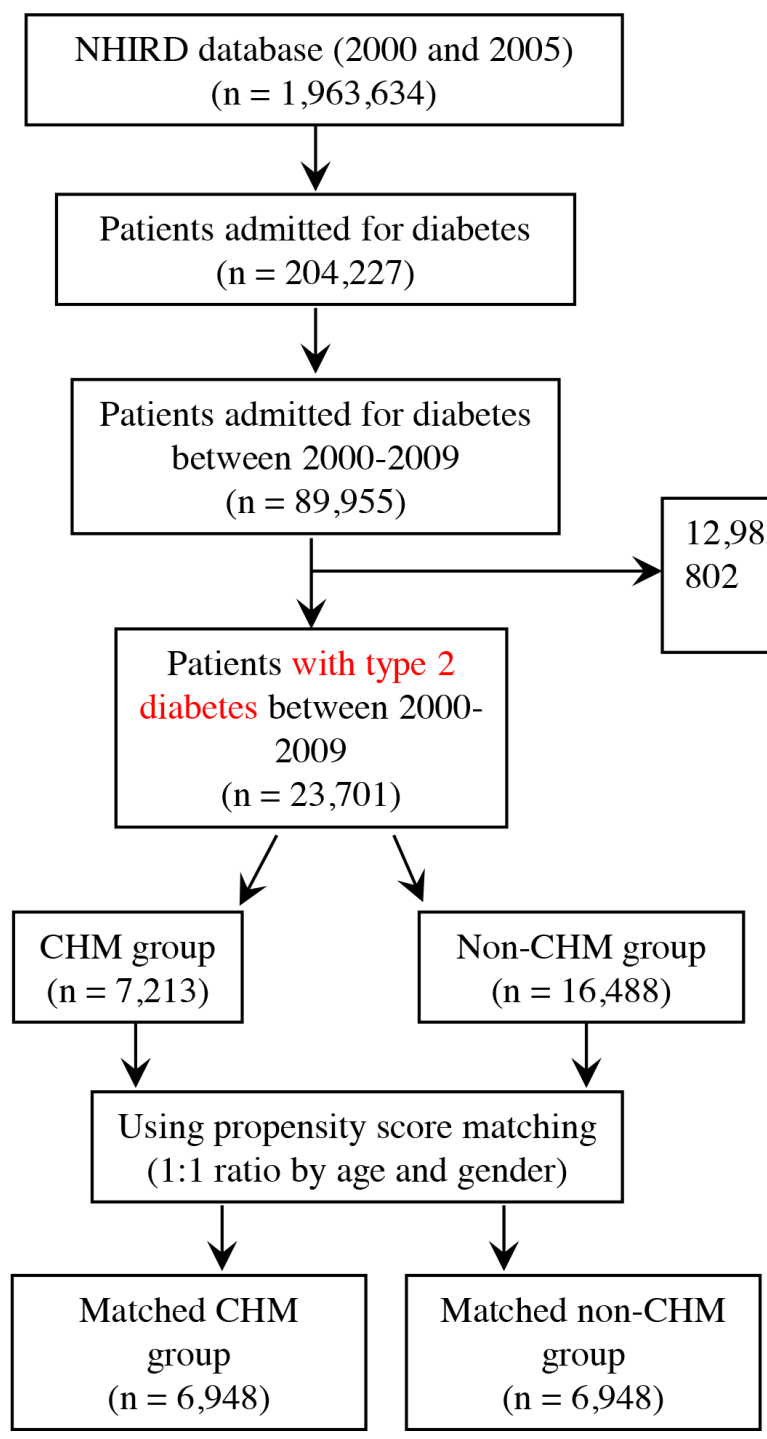

Figure 1: Enrollment of type 2 diabetes patients. Patients with type 2 diabetes were identified for our study cohort after the exclusions listed above. 
Table 1: Baseline characteristics of total subjects and propensity score matched subjects with T2D according to CHM use

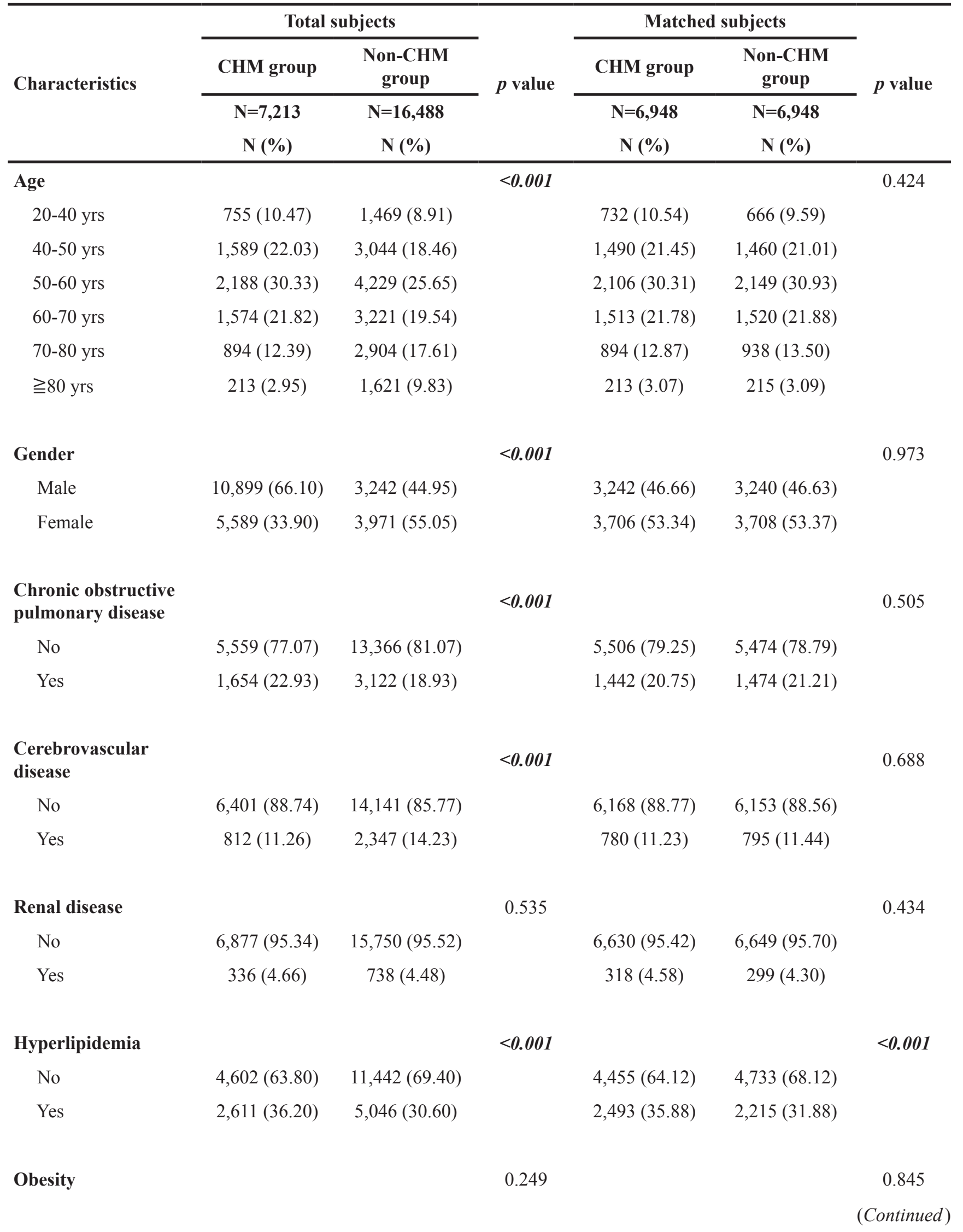




\begin{tabular}{|c|c|c|c|c|c|c|}
\hline \multirow{4}{*}{ Characteristics } & \multicolumn{2}{|c|}{ Total subjects } & \multirow{4}{*}{$p$ value } & \multicolumn{2}{|c|}{ Matched subjects } & \multirow{4}{*}{$p$ value } \\
\hline & CHM group & $\begin{array}{l}\text { Non-CHM } \\
\text { group }\end{array}$ & & CHM group & $\begin{array}{l}\text { Non-CHM } \\
\text { group }\end{array}$ & \\
\hline & $\mathrm{N}=7,213$ & $\mathrm{~N}=16,488$ & & $\mathrm{~N}=6,948$ & $\mathrm{~N}=6,948$ & \\
\hline & $\mathbf{N}(\%)$ & $\mathbf{N}(\%)$ & & $\mathbf{N}(\%)$ & $\mathbf{N}(\%)$ & \\
\hline No & $7,156(99.21)$ & $16,380(99.34)$ & & 6,894 (99.22) & $6,896(99.25)$ & \\
\hline Yes & $57(0.79)$ & $108(0.66)$ & & $54(0.78)$ & $52(0.75)$ & \\
\hline Alcohol-related illness & & & 0.018 & & & 0.911 \\
\hline No & $7,173(99.45)$ & $16,349(99.16)$ & & 6,908 (99.42) & $6,907(99.41)$ & \\
\hline Yes & $40(0.55)$ & $139(0.84)$ & & $40(0.58)$ & $41(0.59)$ & \\
\hline Hypertension & & & $<0.001$ & & & 0.285 \\
\hline No & $3,808(52.79)$ & 7,926 (48.07) & & $3,631(52.26)$ & $3,568(51.35)$ & \\
\hline Yes & $3,405(47.21)$ & $8,562(51.93)$ & & $3,317(47.74)$ & $3,380(48.65)$ & \\
\hline Myocardial infarction & & & $<0.001$ & & & 0.942 \\
\hline No & $7,117(98.67)$ & $16,052(97.36)$ & & $6,852(98.62)$ & $6,853(98.63)$ & \\
\hline Yes & $96(1.33)$ & $436(2.64)$ & & $96(1.38)$ & $95(1.37)$ & \\
\hline $\begin{array}{l}\text { Anti-hypertensives } \\
\text { drug use }\end{array}$ & & & $<0.001$ & & & 0.429 \\
\hline No & $5265(72.99)$ & $12746(77.30)$ & & $5146(74.06)$ & $5105(73.47)$ & \\
\hline Yes & $1948(27.01)$ & $3742(22.70)$ & & $1802(25.94)$ & $1843(26.53)$ & \\
\hline Statin use & & & $<0.001$ & & & 0.976 \\
\hline No & $6571(91.10)$ & $15271(92.62)$ & & $6353(91.44)$ & $6354(91.45)$ & \\
\hline Yes & $642(8.90)$ & $1217(7.38)$ & & $595(8.56)$ & $594(8.55)$ & \\
\hline Insulin use & & & 0.085 & & & 0.178 \\
\hline No & 7196 (99.76) & $16426(99.62)$ & & $6931(99.76)$ & $6938(99.86)$ & \\
\hline Yes & $17(0.24)$ & $62(0.38)$ & & $17(0.24)$ & $10(0.14)$ & \\
\hline Income & & & $<0.001$ & & & $<0.001$ \\
\hline$<$ NT20000 & $2,728(37.82)$ & 7,068 (42.87) & & $2,629(37.84)$ & $2,928(42.14)$ & \\
\hline NT20000 NT30000 & $2,512(34.83)$ & $5,581(33.85)$ & & $2,404(34.60)$ & $2,396(34.48)$ & \\
\hline NT30000 NT40000 & $1,227(17.01)$ & $2,180(13.22)$ & & $1,175(16.91)$ & $995(14.32)$ & \\
\hline \multirow[t]{2}{*}{$>=$ NT40000 } & $746(10.34)$ & $1,659(10.06)$ & & $740(10.65)$ & $629(9.05)$ & \\
\hline & & & & & & (Continued) \\
\hline
\end{tabular}




\begin{tabular}{|c|c|c|c|c|c|c|}
\hline \multirow{4}{*}{ Characteristics } & \multicolumn{2}{|c|}{ Total subjects } & \multirow{4}{*}{$p$ value } & \multicolumn{2}{|c|}{ Matched subjects } & \multirow{4}{*}{$p$ value } \\
\hline & CHM group & $\begin{array}{l}\text { Non-CHM } \\
\text { group }\end{array}$ & & CHM group & $\begin{array}{l}\text { Non-CHM } \\
\text { group }\end{array}$ & \\
\hline & $\mathrm{N}=7,213$ & $\mathrm{~N}=16,488$ & & $\mathrm{~N}=6,948$ & $\mathrm{~N}=6,948$ & \\
\hline & N (\%) & $\mathbf{N}(\%)$ & & N (\%) & $\mathbf{N}(\%)$ & \\
\hline Urbanization level & & & $<0.001$ & & & 0.004 \\
\hline 1 & $3,112(43.14)$ & $6,830(41.42)$ & & $3,003(43.22)$ & $2,975(42.82)$ & \\
\hline 2 & $1,797(24.91)$ & $3,950(23.96)$ & & $1,727(24.86)$ & $1,674(24.09)$ & \\
\hline 3 & $663(9.19)$ & $1,411(8.56)$ & & $641(9.23)$ & $592(8.52)$ & \\
\hline 4 & $623(8.64)$ & $1,558(9.45)$ & & $600(8.64)$ & $573(8.25)$ & \\
\hline 5 & $1,018(14.11)$ & $2,739(16.61)$ & & $977(14.06)$ & $1,134(16.32)$ & \\
\hline
\end{tabular}

$p$ values were obtained by chi-square test. $p$ value $(p<0.05)$ was highlighted in bold italic.

T2D, type 2 diabetes; CHM, Chinese herbal medicine; N, number; NT, new Taiwan dollars.

Urbanization level: 1 indicates the hightest level of urbanization and 5 is the lowest level.

The comorbidities include chronic obstructive pulmonary disease (ICD-9-CM: 490-496), cerebrovascular disease (ICD-

9-CM: 430-438), renal disease (ICD-9-CM: 582, 583-583.7, 585, 586, and 588), hyperlipidemia (ICD-9-CM: 272),

obesity (ICD-9-CM: 278 and 278.01), alcohol-related illness (ICD-9-CM: 303, 305, 305.01, 305.02, 305.03, and V11.3),

hypertension (ICD-9-CM: 401-405), and myocardial infarction (ICD-9-CM: 410 and 412). These comorbidities are

identified before the T2D diagnosis.

Table 2: Hazard ratios $(95 \% \mathrm{CI})$ for diabetic retinopathy when T2D patients were stratified by gender

\begin{tabular}{lcc}
\hline CHM user (Ref: non-CHM user) & Hazard ratio (95\% CI) & $\boldsymbol{p}$ value \\
\hline Overall & $0.88(0.70-1.10)$ & 0.244 \\
Gender & & \\
Male & $0.85(0.52-1.83)$ & 0.511 \\
Female & $0.56(0.36-0.86)$ & $\mathbf{0 . 0 0 8}$ \\
\hline
\end{tabular}

CHM, Chinese herbal medicine; Ref: Reference; T2D, type 2 diabetes; CI, confidence interval.

*Models adjusted for age, comorbidities, anti-hypertensives drug before T2D, and statin before T2D.

Cox's proportional hazards model and Fine \& Grays' model were applied in this analysis.

$p$ value $(p<0.05)$ was highlighted in bold italic.

Based on the information about the most commonly prescribed CHM products, we evaluated their effects on the phosphorylation of p38 MAPK and p44/42 MAPKs (ERK1/2), caused by $\mathrm{H}_{2} \mathrm{O}_{2}$-induced oxidative stress. Human ARPE-19 retina cells were treated with these most commonly used CHM products at the indicated concentrations (Figures 3-6). Insulin was used as the control. The CHM- and insulin-treated cells were then incubated with an $\mathrm{H}_{2} \mathrm{O}_{2}$ solution. As shown in Figures $3 \mathrm{~A}, 4 \mathrm{~A}, 5 \mathrm{~A}$, and $6 \mathrm{~A}$, the human retina cells treated with $\mathrm{H}_{2} \mathrm{O}_{2}$ showed increased phosphorylation of p38 MAPK and p44/42 MAPKs (ERK1/2) when compared with the untreated cells (Lanes 1 and 2). In addition, there were slight increases in the phosphorylation of p38 MAPK and p44/42 MAPKs (ERK1/2) in the insulin $+\mathrm{H}_{2} \mathrm{O}_{2}$-treated cells compared with that in the $\mathrm{H}_{2} \mathrm{O}_{2}$-treated cells (Figures $3 \mathrm{~A}, 4 \mathrm{~A}, 5 \mathrm{~A}$, and $6 \mathrm{~A}$, Lanes 2 and 3 ).

Interestingly, among the top 10 herbal formulations, the $\mathrm{H}_{2} \mathrm{O}_{2}$-induced phosphorylation of p38 MAPK was reduced by JWXYS, SJHXT, GGT, LWDHW, SZRT, YQS, and CXCTS compared with that in the $\mathrm{H}_{2} \mathrm{O}_{2}$-treated cells $\left(P<0.05\right.$; Figures 3B and 4B). The $\mathrm{H}_{2} \mathrm{O}_{2}$-induced phosphorylation of p44/42 MAPKs (ERK1/2) was reduced by JWXYS, SJHXT, GGT, SYGCT, XFZYT, MXSGT, LWDHW, and SZRT compared with that in the $\mathrm{H}_{2} \mathrm{O}_{2}$ treated cells $(P<0.05$; Figure $3 \mathrm{C})$.

Among the top 10 single herbs, the $\mathrm{H}_{2} \mathrm{O}_{2}$-induced phosphorylation of p38 MAPK was reduced by HQin, 
DS, NX, BM, HQ, XF, and THF when compared with that in the $\mathrm{H}_{2} \mathrm{O}_{2}$-treated cells $(P<0.05$; Figures 5B and 6B). The $\mathrm{H}_{2} \mathrm{O}_{2}$-induced phosphorylation of $\mathrm{p} 44 / 42$ MAPKs (ERK1/2) was reduced by HQin, GG, YHS, DS, NX, and $\mathrm{XF}$ when compared with that in the $\mathrm{H}_{2} \mathrm{O}_{2}$-treated cells $(P$ $<0.05$; Figures 5C and 6C).

\section{CHM network for female patients with T2D}

Our results suggested that the cumulative probability of diabetic retinopathy was lower for the CHM users than that for the CHM non-users in the female subgroups (Table 2 and Figure 2). To explore the CHM network and core treatments prescribed for these female patients with T2D, CHM combinations and their constituted networks were identified from the Taiwan NHIRD (Table 4 and Figure 7). The CHM network was analyzed for these patients and found to present complicated relationships among CHM products. During the study period, 1,828 female patients with T2D used CHMs, and 26,977 prescriptions were made by traditional Chinese medicine (TCM) doctors. Among the prescriptions, the top six CHM combinations are shown in Table 4. In addition, CHM network analysis was performed for these patients (Figure 7). Four clusters were found among the top CHM combinations, and each cluster was constituted by a core CHM and its important combinations. JWXYS was the core CHM of cluster 1, which was the largest CHM cluster. In this cluster, JWXYS, DS, XF, and SZRT reduced the $\mathrm{H}_{2} \mathrm{O}_{2}$-induced phosphorylation of both p38 MAPK and p44/42 MAPKs (ERK1/2). In cluster 2, SJHXT was the core CHM, and SJHXT and NX were important CHMs, which both reduced the $\mathrm{H}_{2} \mathrm{O}_{2}$-induced phosphorylation of $\mathrm{p} 38 \mathrm{MAPK}$ and p44/42 MAPKs (ERK1/2). In cluster 3, GGT was

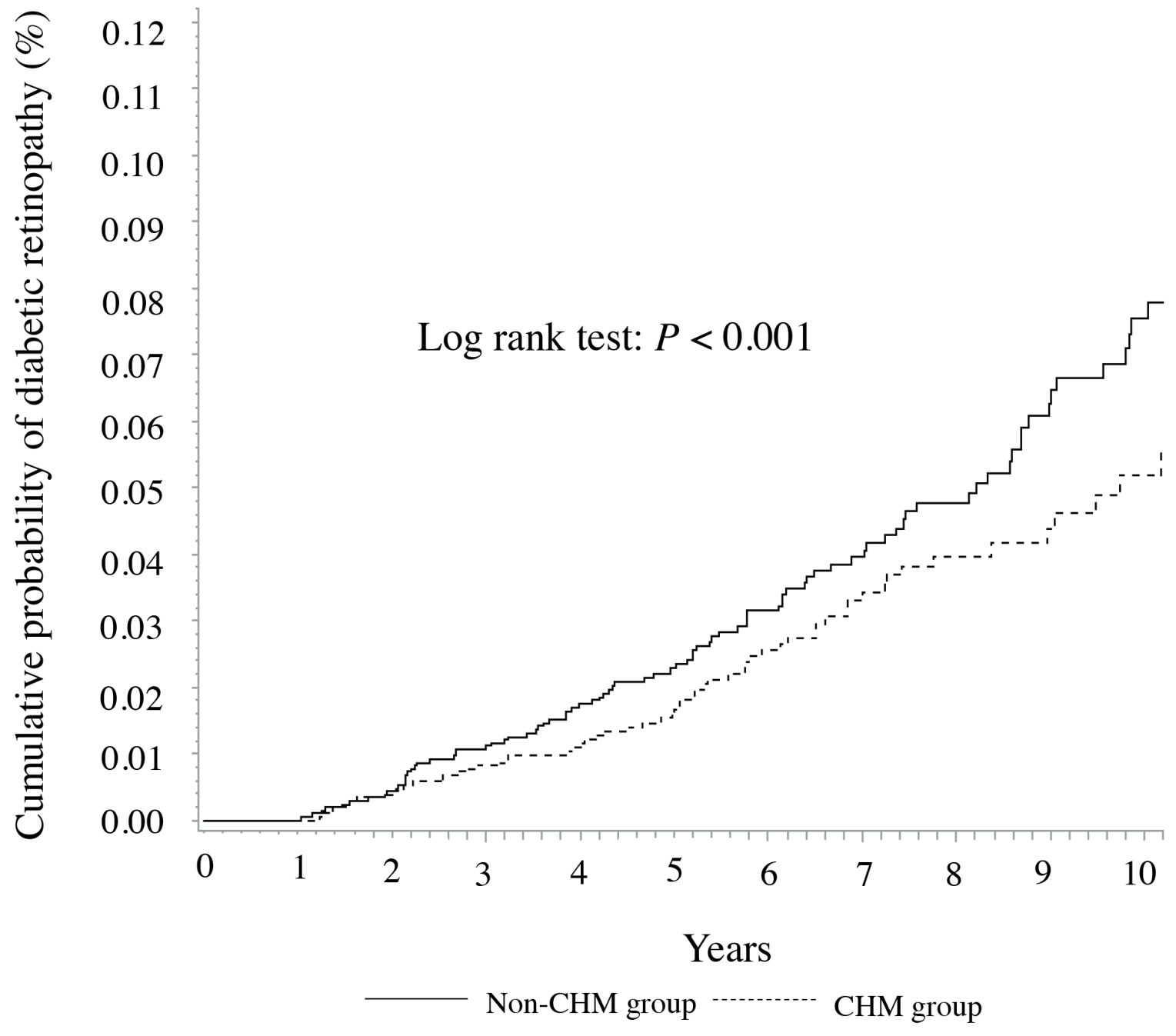

Figure 2: Cumulative probability of diabetic retinopathy in female patients with T2D according to the CHM use. 
A

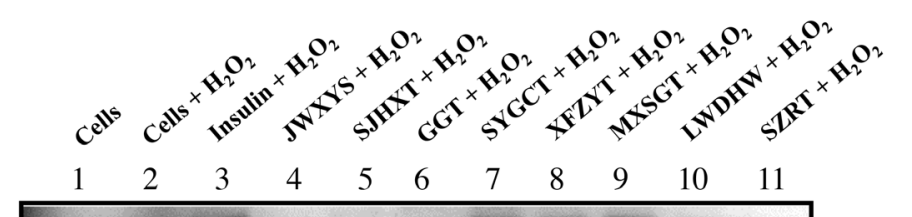

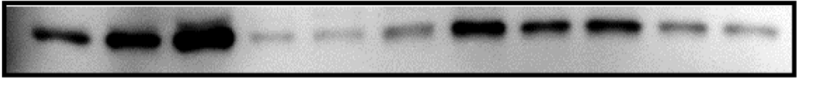
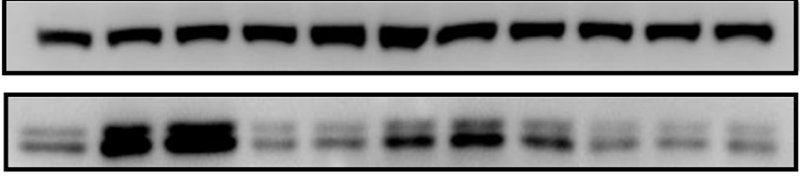

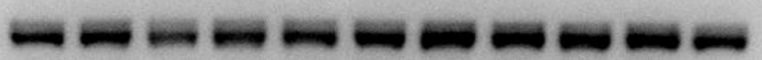

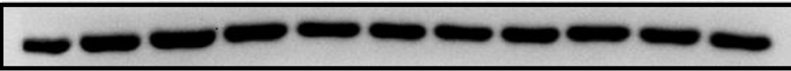

Phospho-p38 MAPK

P38 MAPK

Phospho-p44/42 MAPK

(ERK1/2) (Thr202/Tyr204)

P44/42 MAPK (ERK1/2)

GAPDH

B

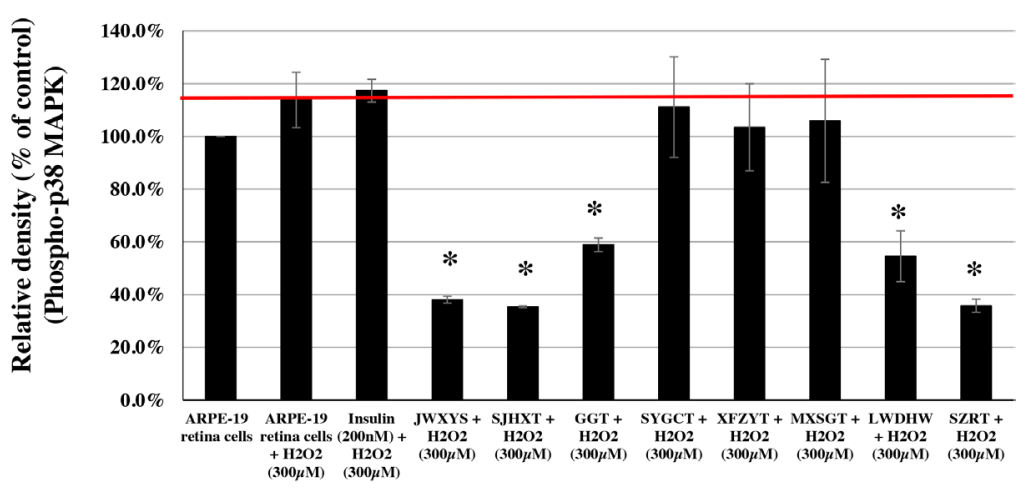

C

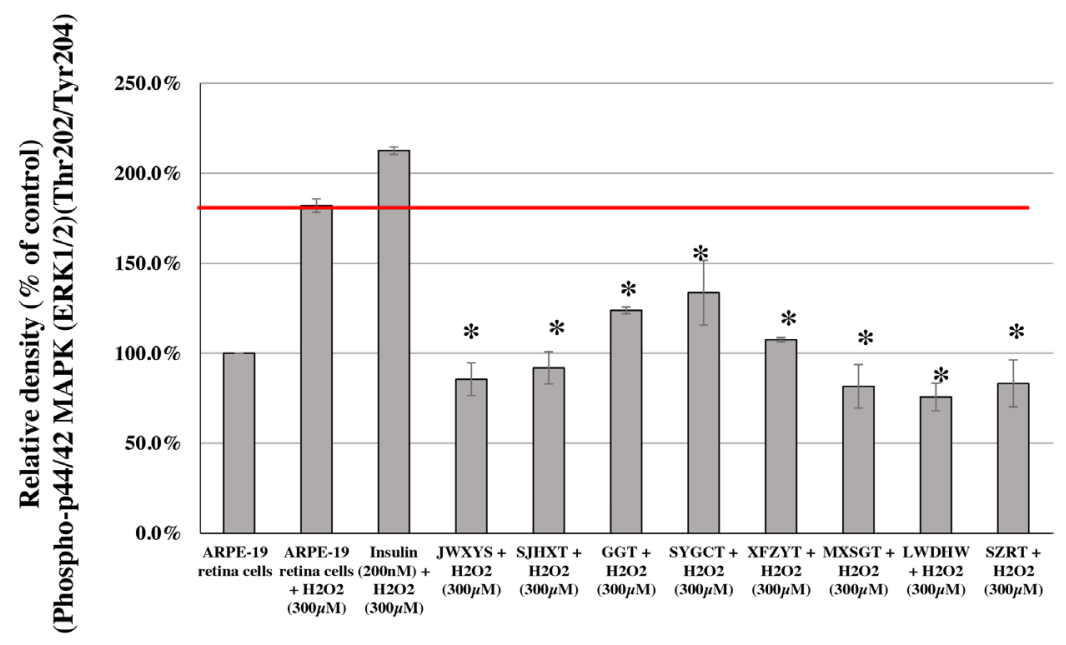

Figure 3: Effects of CHMs (JWXYS, SJHXT, GGT, SYGCT, XFZYT, MXSGT, LWDHW, and SZRT) on $\mathrm{H}_{2} \mathrm{O}_{2}$-treated ARPE-19 cells. Cells treated with insulin $(200 \mathrm{nM})$ were used as controls. The insulin- and CHM-treated cells were then incubated with an $\mathrm{H}_{2} \mathrm{O}_{2}(300 \mu \mathrm{M})$ solution. Western blot analysis was performed by staining membranes with anti-phospho-p38 MAPK, anti-p38 MAPK, anti-phospho-p44/42 MAPK, anti-p44/42 MAPK, and anti-GAPDH antibodies. (A) Western blot analysis of phospho-p38 MAPK, p38 MAPK, phospho-p44/42 MAPK, p44/42 MAPK, and GAPDH protein expression. (B) The ratio of phospho-p38 MAPK to p38 MAPK in various treatment groups versus that in untreated cells. ${ }^{*} P<0.05$. (C) The ratio of phospho-p44/42 MAPKs to $\mathrm{p} 44 / 42$ MAPKs in various treatment groups versus that in untreated cells. $* P<0.05$. 
A
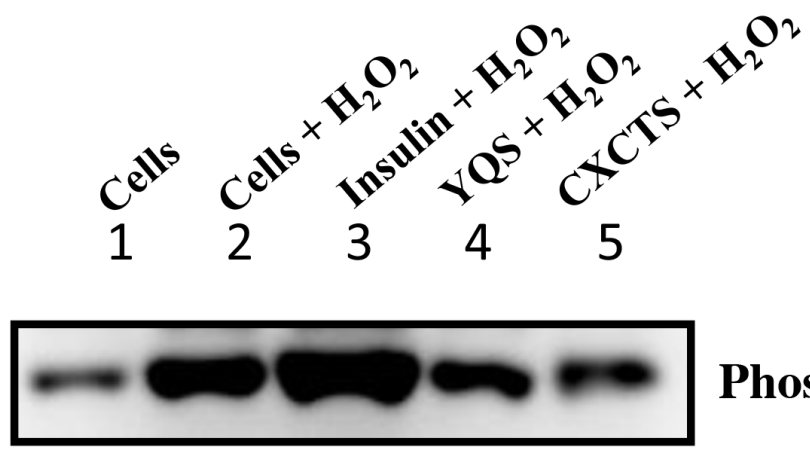

Phospho-p38 MAPK

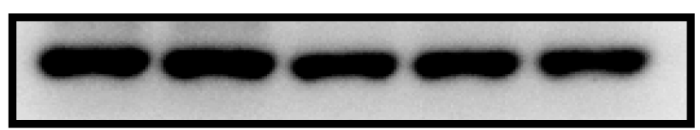

p38 MAPK

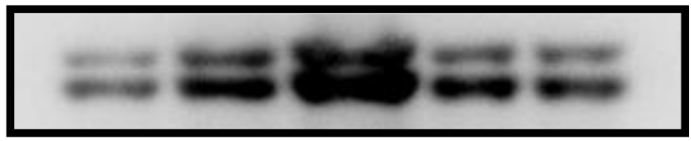

Phospho-p44/42 MAPK

(ERK1/2) (Thr202/Tyr204)

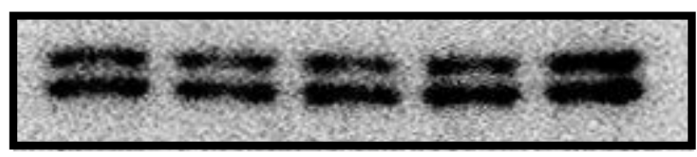

p44/42 MAPK (ERK1/2)

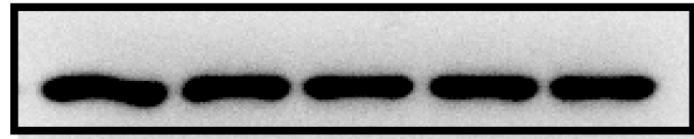

GAPDH

\section{B}

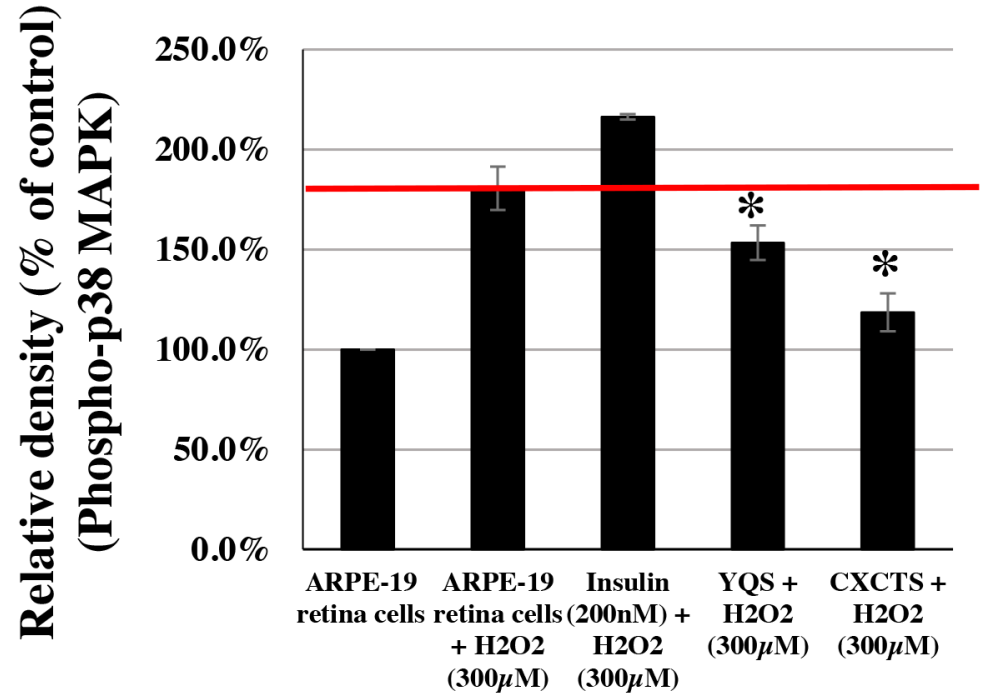

Figure 4: Effects of CHMs (YQS and CXCTS) on $\mathbf{H}_{2} \mathbf{O}_{2}$-treated ARPE-19 cells. Cells treated with insulin (200 nM) were used as controls. The insulin- and CHM-treated cells were then incubated with an $\mathrm{H}_{2} \mathrm{O}_{2}(300 \mu \mathrm{M})$ solution. Western blot analysis was performed by staining membranes with anti-phospho-p38 MAPK, anti-p38 MAPK, anti-phospho-p44/42 MAPK, anti-p44/42 MAPK, and antiGAPDH antibodies. (A) Western blot analysis of phospho-p38 MAPK, p38 MAPK, phospho-p44/42 MAPK, p44/42 MAPK, and GAPDH protein expression. (B) The ratio of phospho-p38 MAPK to p38 MAPK in various treatment groups versus that in untreated cells. ${ }^{*} P<0.05$. 


\section{C}

Figure 4 (Continued): (C) The ratio of phospho-p44/42 MAPKs to p44/42 MAPKs in various treatment groups versus that in untreated cells.

the core CHM and the only CHM that reduced the $\mathrm{H}_{2} \mathrm{O}_{2}$ induced phosphorylation of both $\mathrm{p} 38$ MAPK and p44/42 MAPKs (ERK1/2). In cluster 4, HQin was the core $\mathrm{CHM}$ and the only CHM that reduced the $\mathrm{H}_{2} \mathrm{O}_{2}$-induced phosphorylation of p38 MAPK and p44/42 MAPKs (ERK1/2). The following interconnections were also observed among these clusters: cluster 4 was connected to cluster 1 , cluster 1 was connected to cluster 2, and cluster 2 was connected to cluster 3 (Figure 7).

\section{DISCUSSION}

This study showed that adjunctive CHM treatment might reduce the occurrence of diabetic retinopathy among female patients with T2D. The herbal formulas, single herbs, and their combinations, most commonly used by these patients, were identified and evaluated in terms of their protective effects against oxidative stress and inflammation in ARPE-19 retina cells. In addition, the core $\mathrm{CHMs}$, CHM clusters, and CHM cluster interconnections were identified and presented as a consensus CHM prescription pattern for the target disease. This is valuable information for TCM doctors and researchers that can be used in the clinic and in further investigations.
To our knowledge, this is the first population-based pharmacoepidemiological study that focused on the CHM effects on diabetic retinopathy in T2D patients. Our results suggested that adjunctive CHM treatment may reduce the occurrence of diabetic retinopathy by reducing oxidative stress in human retina cells.

Our results showed that among the female patients, the cumulative probability of diabetic retinopathy was lower in CHM users than in CHM non-users. We also found that there were significantly different CHM prescription patterns and networks between female and male patients (Supplementary Figure 1). For the female patients, JWXYS was the core CHM in cluster 1. Among CHMs from this cluster, JWXYS, DS, XF, and SZRT reduced the $\mathrm{H}_{2} \mathrm{O}_{2}$-induced phosphorylation of both $\mathrm{p} 38$ MAPK and p44/42 MAPKs (ERK1/2) in retina cells in vitro. Furthermore, cells treated with JWXYS, DS, and $\mathrm{XF}$ also showed reduced ROS levels by flow cytometry, compared with those in $\mathrm{H}_{2} \mathrm{O}_{2}$-treated cells. JWXYS is composed of 10 single herbs and has been prescribed for many different conditions, including anorexia, dry eyes, headache, hot flashes, irregular menstruation, nervousness, night sweating, and palpitations, as well as for hepatoprotection [36-40]. Furthermore, JWXYS has been 
used for many different diseases, including hypertension with T2D, systemic lupus erythematosus, urolithiasis, chronic hepatitis B infection, liver cancer, colon cancer, breast cancer, sleep disorders, major depressive disorders, and dementia [28, 41-48]. Among the 10 single herbs from this formulation, Dang-Gui (Angelica sinensis (Oliv.) Diels) and Bai-Shao (Paeonia lactiflora Pall.) are the two major herbs. Dang-Gui (A. sinensis (Oliv.) Diels) contains two major natural compounds, ferulic acid and coniferyl ferulate [49], exhibiting antioxidant and antiinflammatory activities [50, 51]. Bai-Shao (P. lactiflora Pall.) contains paeoniflorin and albiflorin [52, 53], both showing antioxidant and anti-inflammatory activities [52, 54]. Therefore, there are at least four natural compounds

A

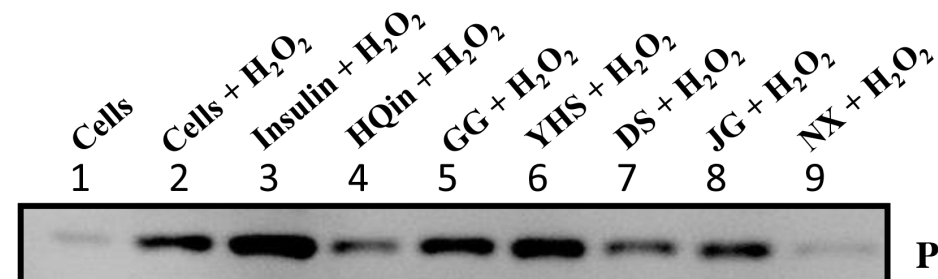

Phospho-p38 MAPK

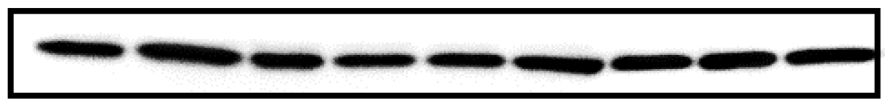

p38 MAPK

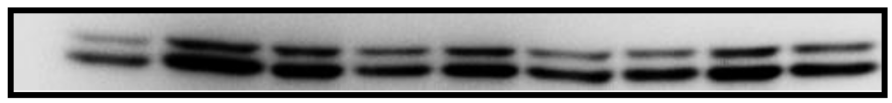

Phospho-p44/42 MAPK

(ERK1/2) (Thr202/Tyr204)

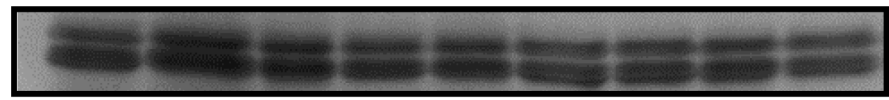

P44/42 MAPK (ERK1/2)

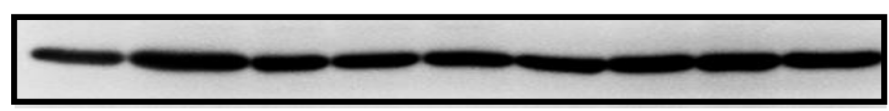

\section{GAPDH}

B

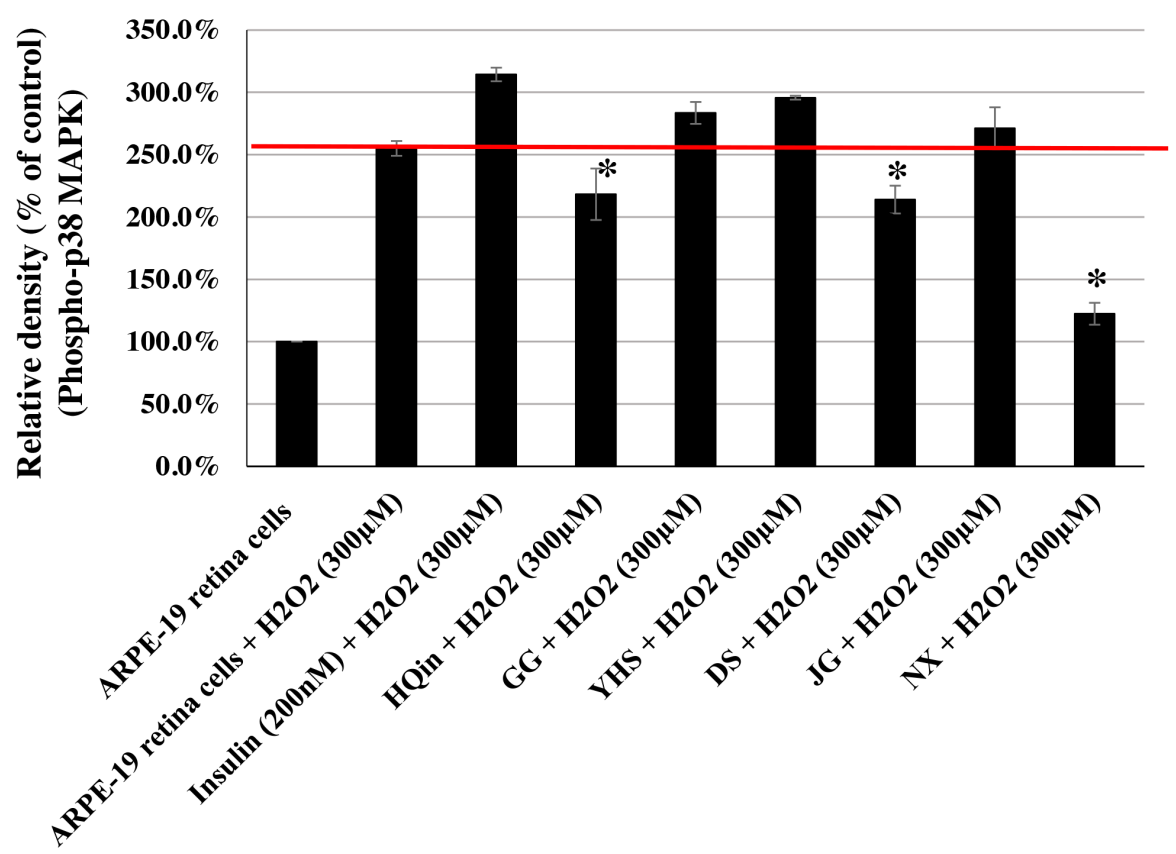

Figure 5: Effects of CHMs (HQin, GG, YHS, DS, JG, and NX) on $\mathrm{H}_{2} \mathrm{O}_{2}$-treated ARPE-19 cells. Cells treated with insulin $(200 \mathrm{nM})$ were used as controls. The insulin- and CHM-treated cells were then incubated with an $\mathrm{H}_{2} \mathrm{O}_{2}(300 \mu \mathrm{M})$ solution. Western blot analysis was performed by staining membranes with anti-phospho-p38 MAPK, anti-p38 MAPK, anti-phospho-p44/42 MAPK, anti-p44/42 MAPK, and anti-GAPDH antibodies. (A) Western blot analysis of phospho-p38 MAPK, p38 MAPK, phospho-p44/42 MAPK, p44/42 MAPK, and GAPDH protein expression. (B) The ratio of phospho-p38 MAPK to p38 MAPK in various treatment groups versus that in untreated cells. $* P<0.05$. 


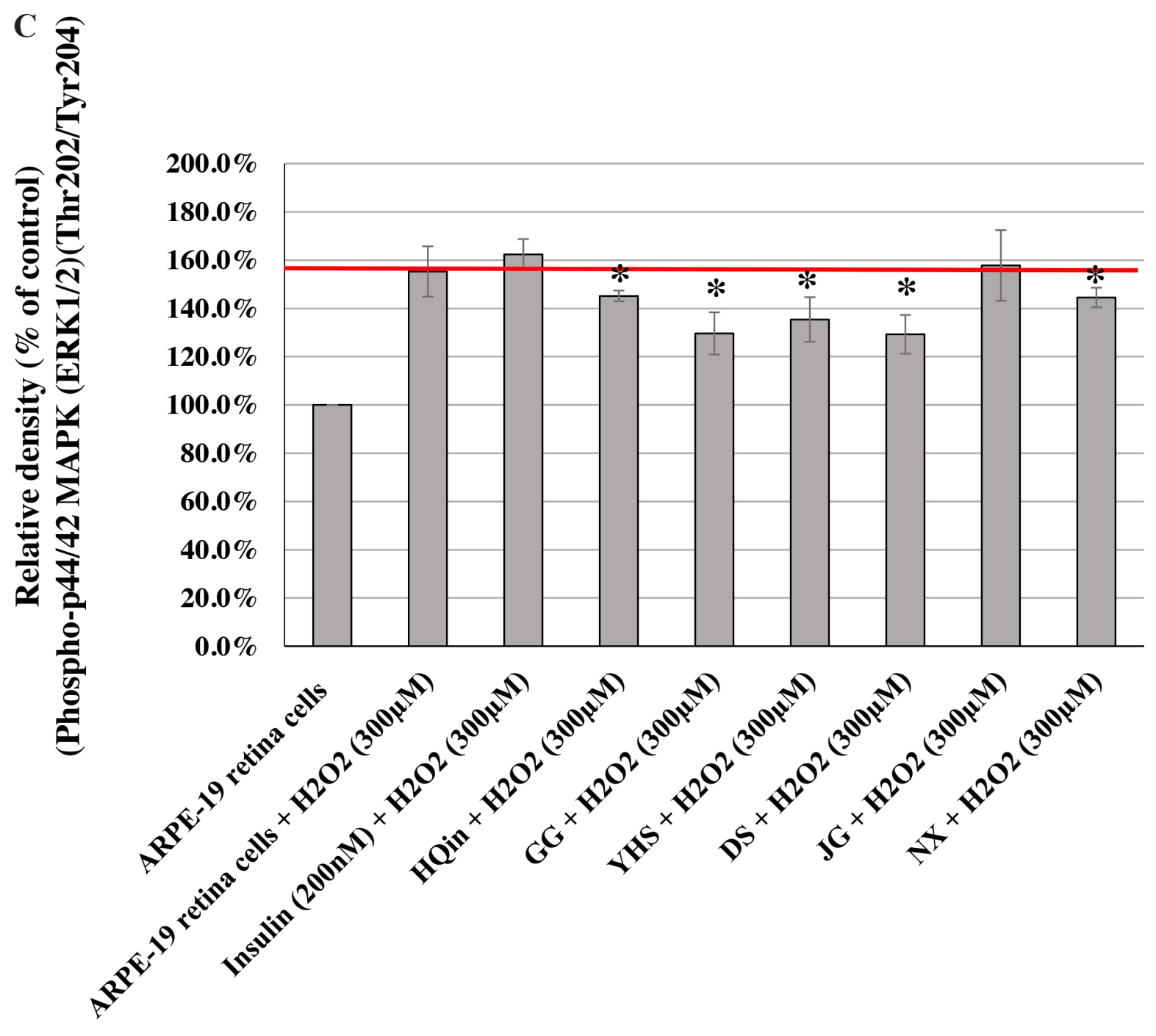

Figure 5 (Continued): (C) The ratio of phospho-p44/42 MAPKs to p44/42 MAPKs in various treatment groups versus that in untreated cells. ${ }^{*} \mathrm{P}<0.05$.

with antioxidant and anti-inflammatory activities, ferulic acid, coniferyl ferulate, paeoniflorin, and albiflorin, in JWXYS (cluster 1). We examined their effects on ROS levels in retina cells by flow cytometry and found that cells treated with these natural compounds demonstrated reduced ROS levels compared with those in $\mathrm{H}_{2} \mathrm{O}_{2}$-treated cells. DS (Salvia miltiorrhiza Bunge) contains diterpenoid quinones, hydrophilic phenolic acids, and essential oils and shows antioxidant, neuroprotective, antifibrotic, antiinflammatory, and antineoplastic activities $[55,56]$. XF (Cyperus rotundus L.) is a medicinal herb traditionally used to treat various clinical conditions, including diarrhea, diabetes, pyresis, inflammation, malaria, as well as stomach and bowel disorders [57]. XF (C. rotundus L.) contains essential oils, phenolic acids, ascorbic acid, and flavonoids in tubers and rhizomes and exhibits antiinflammatory activities [58].
In cluster 2, SJHXT was the core CHM. SJHXT and $\mathrm{NX}$ were found to be important CHMs that reduced the $\mathrm{H}_{2} \mathrm{O}_{2}$-induced phosphorylation of both p38 MAPK and p44/42 MAPKs (ERK1/2). SJHXT is composed of 17 single herbs and has been prescribed for hundreds years for the treatment of chronic pain syndromes, including fractures [59], breast cancer [47], and prostate cancer [60]. Its pharmacological activities include anti-inflammatory and analgesic effects [61], antihypersensitivity activity [62], and the ability to increase blood circulation [63]. Among the 17 single herbs in this formulation, DangGui (A. sinensis (Oliv.) Diels) and Bai-Shao (P. lactiflora Pall.) are the two major single herbs. Therefore, similar to JWXYS, ferulic acid, coniferyl ferulate, paeoniflorin, and albiflorin are the major components of SJHXT (cluster 2), which demonstrated ROS-reducing effects in retina cells treated with $\mathrm{H}_{2} \mathrm{O}_{2}$. NX (Achyranthes bidentata Blume) is often used in TCM for the treatment of arthritis since it 
A
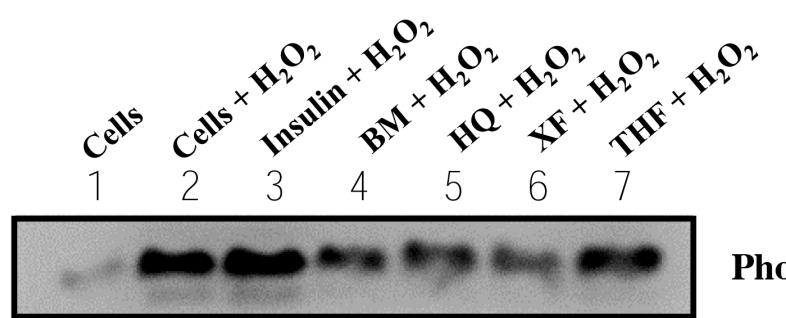

Phospho-p38 MAPK

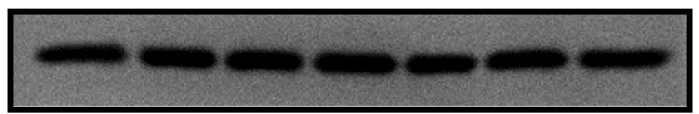

p38 MAPK

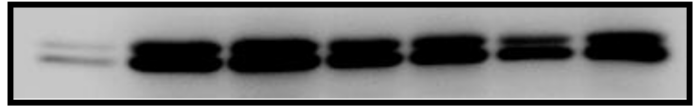

Phospho-p44/42 MAPK

(ERK1/2) (Thr202/Tyr204)

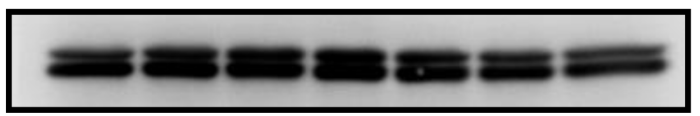

p44/42 MAPK (ERK1/2)

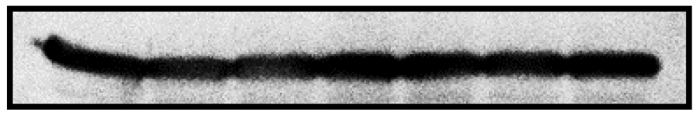

GAPDH

B

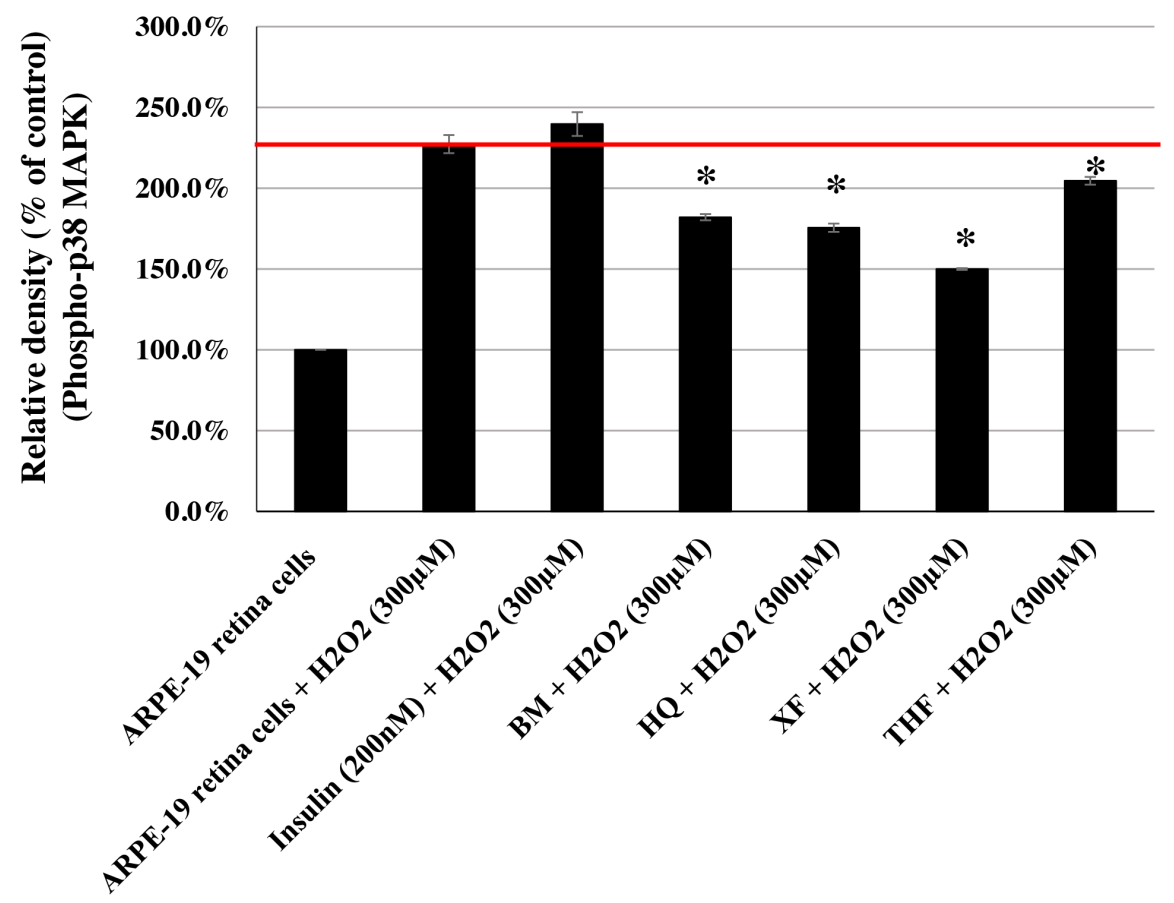

Figure 6: Effects of CHMs (BM, THF, HQ, and XF) on $\mathbf{H}_{2} \mathbf{O}_{2}$-treated ARPE-19 cells. Cells treated with insulin (200 nM) were used as controls. The insulin- and CHM-treated cells were then incubated with an $\mathrm{H}_{2} \mathrm{O}_{2}(300 \mu \mathrm{M})$ solution. Western blot analysis was performed by staining membranes with anti-phospho-p38 MAPK, anti-p38 MAPK, anti-phospho-p44/42 MAPK, anti-p44/42 MAPK, and anti-GAPDH antibodies. (A) Western blot analysis of phospho-p38 MAPK, p38 MAPK, phospho-p44/42 MAPK, p44/42 MAPK, and GAPDH protein expression. (B) The ratio of phospho-p38 MAPK to p38 MAPK in various treatment groups versus that in untreated cells. ${ }^{*} P<0.05$.

(Continued) 


\section{C}

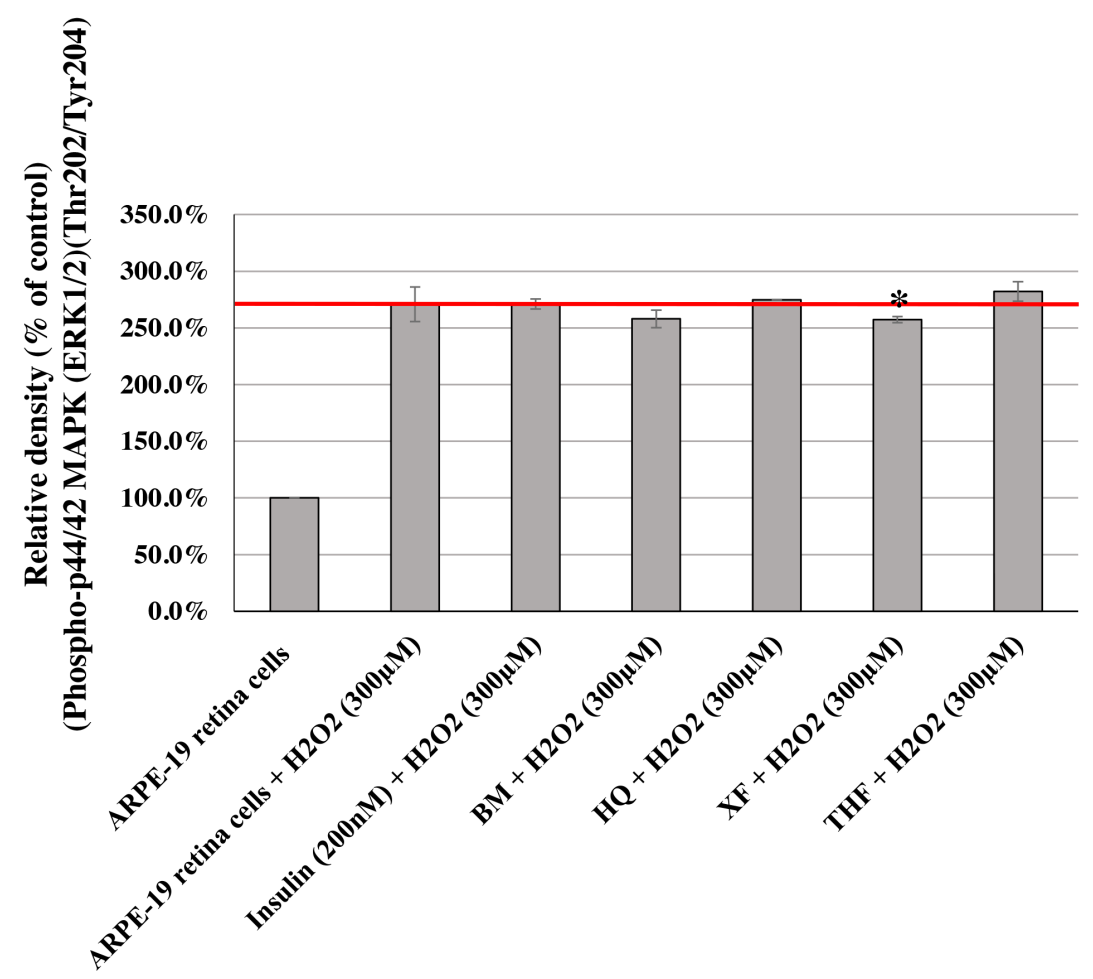

Figure 6 (Continued): (C) The ratio of phospho-p44/42 MAPKs to p44/42 MAPKs in various treatment groups versus that in untreated cells. ${ }^{*} \mathrm{P}<0.05$.

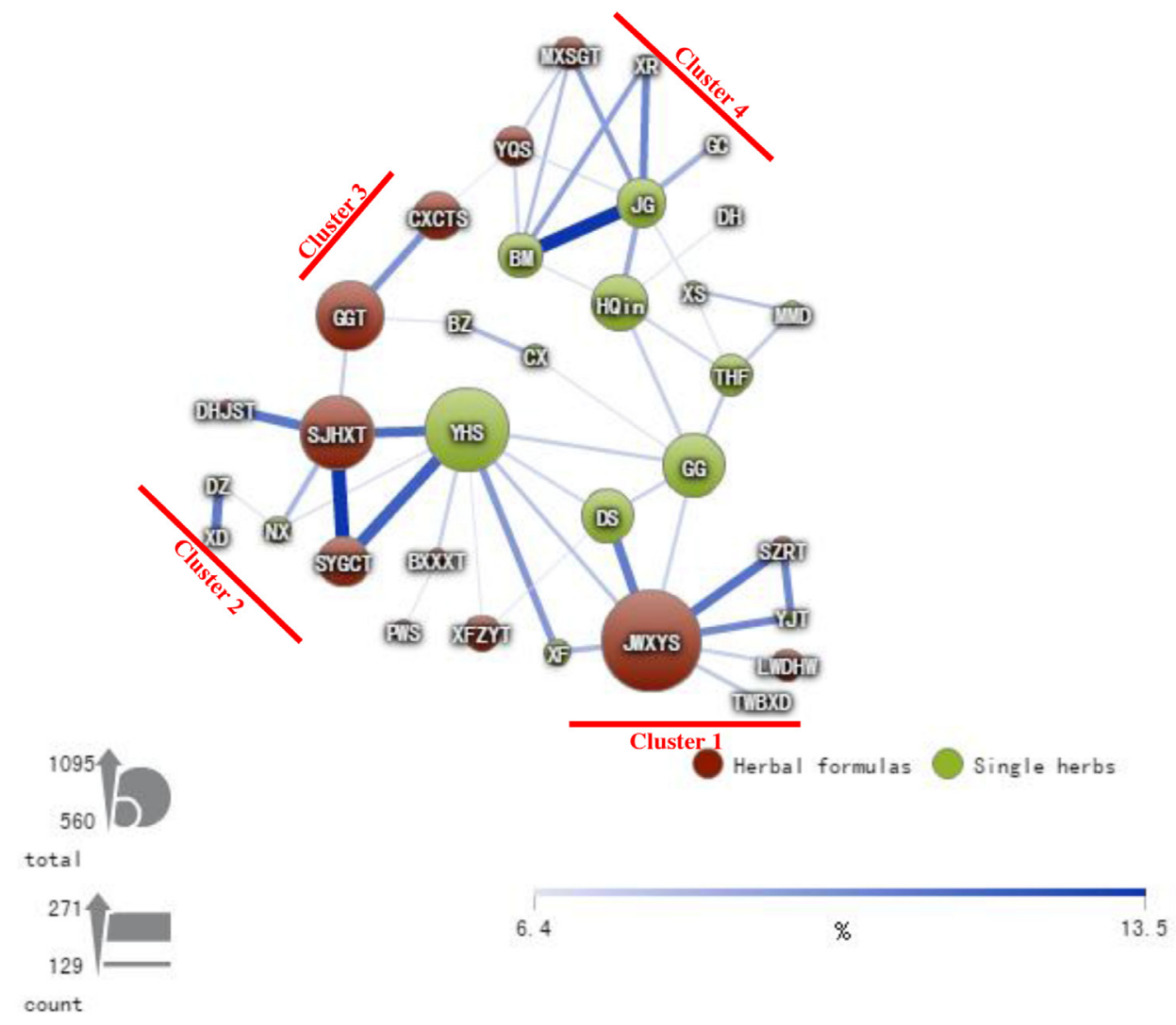

Figure 7: CHM network for female patients with T2D. The connection lines between CHMs represent user numbers for CHM combinations. The connection between CHMs is more important when the connection line is thicker and darker. The size of the circle represents the frequency of prescriptions for each CHM. 
Table 3: Ten most commonly used herbal formulas and single herbs for female patients with T2D

\begin{tabular}{|c|c|c|c|c|c|c|c|c|c|c|}
\hline Formulas & $\begin{array}{c}\text { Pin-yin } \\
\text { name } \\
\text { (shorten } \\
\text { name) }\end{array}$ & $\begin{array}{l}\text { Chinese } \\
\text { name }\end{array}$ & $\begin{array}{c}\text { Number of } \\
\text { herbs }\end{array}$ & $\begin{array}{l}\text { Composition (Pin-yin name (latin name; } \\
\text { botanical plant name)) }\end{array}$ & $\begin{array}{c}\text { User } \\
\text { number }\end{array}$ & $\begin{array}{l}\text { Percentage } \\
\text { of user } \\
\text { number }\end{array}$ & $\begin{array}{c}\text { Frequency } \\
\text { of } \\
\text { prescription }\end{array}$ & $\begin{array}{l}\text { Person- } \\
\text { year }\end{array}$ & $\begin{array}{c}\text { Average } \\
\text { drug dose } \\
\text { per day } \\
\text { (g) }\end{array}$ & $\begin{array}{c}\text { Average } \\
\text { duration for } \\
\text { prescription } \\
\text { (days) }\end{array}$ \\
\hline Total & & & & & 2068 & 100 & 96735 & 12847.3 & 12.2 & 7.2 \\
\hline $\begin{array}{l}\text { Herbal } \\
\text { formula }^{a}\end{array}$ & & & & & 2064 & 99.8 & 93106 & 12831.2 & 9.4 & 7.2 \\
\hline
\end{tabular}

$\begin{array}{ccc}\text { Jia-Wei- } & & \\ \text { Xiao- } & \text { 加味逍 } & \\ \text { Yao-San } & \text { 遙散 } & 10 \\ \text { (JWXYS) } & & \end{array}$

Dang-Gui (Radix Angelicae Sinensi; Angelica sinensis (Oliv.) Diels), Bai-Shao (Radix Paeoniae Alba; Paeonia lactiflora Pall.), Fu-Ling (Poria; Wolfiporia extensa (Peck) Ginns), Bai-Zhu (Rhizoma Atractylodis Macrocephalae; Atractylodes macrocephala Koidz.), Chai-Hu (Radix

Bupleuri; Bupleurum falcatum L.),

Mu-Dan-Pi (Cortex Moutan; Moutan

officinalis (L.) Lindl. \& Paxton), Zhi-Zi

(Fructus Gardeniae; Gardenia jasminoides

J.Ellis), Gan-Cao (Radix Glycyrrhizae

Preparata; Glycyrrhiza uralensis Fisch.),

Bo-He (Herba Menthae Haplocalycis;

Mentha arvensis L.), Sheng-Jiang

(Rhizoma Zingiberis Recens; Zingiber officinale Roscoe)

Shu-Jing- $\quad$ 舒經活 $17 \quad$ Dang-Gui (Radix Angelicae Sinensi;

Huo- 血湯

Xue-Tang

(SJHXT)

Ge-Gen-

Tang

(GGT)

葛根湯 7

Shao-

Yao-Gan- 苟藥甘

Cao-Tang 草湯

(SYGCT)
Shao (Radix Paeoniae Alba; Paeonia

lactiflora Pall.), Chuan-Xiong (Rhizoma Chuanxiong; Ligusticum sinense

Oliv.), Di-Huang (Radix Rehmanniae;

Rehmannia glutinosa (Gaertn.) DC.), TaoRen (Semen Persicae; Prunus persica (L.)

Batsch), Bai-Zhu (Rhizoma Atractylodis;

Atractylodes macrocephala Koidz.),

Fu-Ling (Poria; Wolfiporia extensa

(Peck) Ginns), Niu-Xi (Radix Achyranthis

Bidentatae; Achyranthes bidentata Blume)

Wei-Ling-Xian (Radix Clematidis;

Clematis chinensis Osbeck), Han-

Fang-Ji (Radix Stephaniae Tetrandrae;

Stephania tetrandra S.Moore), Qiang-

Huo (Rhizoma seu Radix Notopterygii

Notopterygium forbesii var. oviforme

(Shan) H.T. Chang), Fang-Feng (Radix

Saposhnikoviae; Saposhnikovia divaricata

(Turcz.) Schischk.), Long-Dan-Cao (Radix

Gentianae; Gentiana lutea L.), Bai-Zhi

(Radix Angelicae Dahuricae; Angelica

dahurica (Hoffm.) Benth. \& Hook.f. ex

Franch. \& Sav.), Chen-Pi (Pericarpium

Citri Reticulatae; Citrus reticulata

Blanco), Gan-Cao (Radix Glycyrrhizae

Preparata; Glycyrrhiza uralensis Fisch.),

Sheng-Jiang (Rhizoma Zingiberis Recens; Zingiber officinale Roscoe)

Ge-Gen (Radix Puerariae; Pueraria lobata (Willd.) Ohwi), Ma-Huang (Herba Ephedrae; Ephedra vulgaris Rich.), GuiZhi (Cinnamomi ramulus; Cinnamomum

cassia (L.) J.Prest), Bai-Shao (Radix

Paeoniae Alba; Paeonia lactiflora Pall.),

Sheng-Jiang (Rhizoma Zingiberis Recens;

Zingiber officinale Roscoe), Da-Zao

(Fructus Jujube; Ziziphus jujuba Mill.),

Gan-Cao (Radix Glycyrrhizae Preparata; Glycyrrhiza uralensis Fisch.)

Bai-Shao (Radix Paeoniae Alba; Paeonia lactiflora Pall.), Gan-Cao (Radix

Glycyrrhizae Preparata; Glycyrrhiza uralensis Fisch.)
Angelica sinensis (Oliv.) Diels), Bai-
932

4

7.4

$\begin{array}{llllll}904 & 43.7 & 4658 & 5994.8 & 4.2 & 6.5\end{array}$

801

38.7

3738

5373.8

6.4

(Continued) 


\begin{tabular}{|c|c|c|c|c|c|c|c|c|c|c|}
\hline Formulas & $\begin{array}{c}\text { Pin-yin } \\
\text { name } \\
\text { (shorten } \\
\text { name) }\end{array}$ & $\begin{array}{l}\text { Chinese } \\
\text { name }\end{array}$ & $\begin{array}{l}\text { Number of } \\
\text { herbs }\end{array}$ & $\begin{array}{l}\text { Composition (Pin-yin name (latin name; } \\
\text { botanical plant name)) }\end{array}$ & $\begin{array}{c}\text { User } \\
\text { number }\end{array}$ & $\begin{array}{c}\text { Percentage } \\
\text { of user } \\
\text { number }\end{array}$ & $\begin{array}{c}\text { Frequency } \\
\text { of } \\
\text { prescription }\end{array}$ & $\begin{array}{l}\text { Person- } \\
\text { year }\end{array}$ & $\begin{array}{c}\text { Average } \\
\text { drug dose } \\
\text { per day } \\
\text { (g) }\end{array}$ & $\begin{array}{c}\text { Average } \\
\text { duration for } \\
\text { prescription } \\
\text { (days) }\end{array}$ \\
\hline & $\begin{array}{c}\text { Chuan- } \\
\text { Xiong- } \\
\text { Cha- } \\
\text { Tiao-San } \\
\text { (CXCTS) }\end{array}$ & $\begin{array}{l}\text { 川芎茶 } \\
\text { 調散 }\end{array}$ & 10 & $\begin{array}{c}\text { Bo-He (Herba Menthae Haplocalycis; } \\
\text { Mentha arvensis L.), Chuan-Xiong } \\
\text { (Rhizoma Chuanxiong; Ligusticum } \\
\text { sinense Oliv.), Bai-Zhi (Radix Angelicae } \\
\text { Dahuricae; Angelica dahurica (Hoffm.) } \\
\text { Benth. \& Hook.f. ex Franch. \& Sav.), } \\
\text { Qiang-Huo (Rhizoma seu Radix } \\
\text { Notopterygii; Notopterygium forbesii var. } \\
\text { oviforme (Shan) H.T. Chang), Xi-Xin } \\
\text { (Herba cum Radix Asari; Asarum sieboldii } \\
\text { Miq.), Xiang-Fu (Rhizoma Cyperi; } \\
\text { Cyperus rotundus L.), Jing-Jie (Herba } \\
\text { Schizonepetae; Schizonepeta tenuifolia } \\
\text { (Benth.) Briq.), Fang-Feng (Radix } \\
\text { Saposhnikoviae; Saposhnikovia divaricata } \\
\text { (Turcz.) Schischk.), Gan-Cao (Radix } \\
\text { Glycyrrhizae Preparata; Glycyrrhiza } \\
\text { uralensis Fisch.), Lu-Cha (Folium } \\
\text { Camelliae Sinensis; Camellia sinensis (L.) } \\
\text { Kuntze) }\end{array}$ & 786 & 38 & 4687 & 5323.6 & 4.3 & 6.2 \\
\hline & $\begin{array}{c}\text { Yin-Qiao- } \\
\text { San (YQS) }\end{array}$ & 銀堯羽散 & 10 & $\begin{array}{l}\text { Jin-Yin-Hua (Flos Lonicerae; Lonicera } \\
\text { japonica Thunb.), Lian-Qiao (Fructus } \\
\text { Forsythiae; Forsythia suspensa (Thunb.) } \\
\text { Vahl), Jie-Geng (Radix Platycodi; } \\
\text { Platycodon grandiflorus (Jacq.) A.DC.), } \\
\text { Niu Bang Zi (Fructus Arctii; Arctium } \\
\text { lappa L.), Bo-He (Herba Menthae } \\
\text { Haplocalycis; Mentha arvensis L.), Dan- } \\
\text { Dou-Chi (Semen Sojae Praeparatum; } \\
\text { Glycine max (L.) Merr.), Dan-Zhu-Ye } \\
\text { (Herba Lophatheri; Lophatherum gracile } \\
\text { Brongn.), Jing-Jie (Herba Schizonepetae; } \\
\text { Schizonepeta tenuifolia (Benth.) Briq.), } \\
\text { Lu-Gen (Rhizoma Phragmitis; Phragmites } \\
\text { communis Trin.), Gan-Cao (Radix } \\
\text { Glycyrrhizae Preparata; Glycyrrhiza } \\
\text { uralensis Fisch.) }\end{array}$ & 733 & 35.4 & 3490 & 4969.8 & 3.8 & 5.9 \\
\hline & $\begin{array}{c}\text { Xue-Fu- } \\
\text { Zhu-Yu- } \\
\text { Tang } \\
\text { (XFZYT) }\end{array}$ & $\begin{array}{l}\text { 血府逐 } \\
\text { 瘀湯 }\end{array}$ & 11 & $\begin{array}{l}\text { Tao-Ren (Semen Persicae; Prunus persica } \\
\text { (L.) Batsch), Hong-Hua (Flos Carthami; } \\
\text { Carthamus tinctorius L.), Dang-Gui } \\
\text { (Radix Angelicae Sinensi; Angelica } \\
\text { sinensis (Oliv.) Diels), Chuan-Xiong } \\
\text { (Rhizoma Chuanxiong; Ligusticum sinense } \\
\text { Oliv.), Chi-Shao (Radix Paeoniae Rubra; } \\
\text { Paeonia lactiflora Pall.), Chuan-Niu-Xi } \\
\text { (Radix Cyathulae; Achyranthes bidentata } \\
\text { Blume), Chai-Hu (Radix Bupleuri; } \\
\text { Bupleurum falcatum L.), Jie-Geng (Radix } \\
\text { Platycodi; Platycodon grandiflorus } \\
\text { (Jacq.) A.DC.), Zhi-Shi (Fructus Aurantii } \\
\text { Immaturus; Citrus aurantium L.), } \\
\text { Sheng-Di-Huang (Radix Rehmanniae; } \\
\text { Rehmannia glutinosa (Gaertn.) DC.), } \\
\text { Gan-Cao (Radix Glycyrrhizae Preparata; } \\
\text { Glycyrrhiza uralensis Fisch.) }\end{array}$ & 716 & 34.6 & 3563 & 4771.1 & 3.6 & 8.2 \\
\hline & $\begin{array}{c}\text { Ma-Xing- } \\
\text { Shi-Gan- } \\
\text { Tang } \\
\text { (MXSGT) }\end{array}$ & $\begin{array}{l}\text { 麻杏石 } \\
\text { 甘湯 }\end{array}$ & 4 & $\begin{array}{c}\text { Ma-Huang (Herba Ephedrae; Ephedra } \\
\text { sinica Stapf), Xing-Ren (Semen } \\
\text { Armeniacae; Prunus armeniaca L.), } \\
\text { Shi-Gao (Gypsum Fibrosum), Gan- } \\
\text { Cao (Radix Glycyrrhizae Preparata; } \\
\text { Glycyrrhiza uralensis Fisch.) }\end{array}$ & 699 & 33.8 & 2819 & 4755.3 & 3.7 & 6 \\
\hline & $\begin{array}{c}\text { Liu-Wei- } \\
\text { Di-Huang- } \\
\text { Wan } \\
\text { (LWDHW) }\end{array}$ & $\begin{array}{l}\text { 六味地 } \\
\text { 黄丸 }\end{array}$ & 6 & $\begin{array}{c}\text { Shu-Di-Huang (Radix Rehmanniae } \\
\text { Preparata; Rehmannia glutinosa } \\
\text { (Gaertn.) DC.), Shan-Zhu-Yu (Fructus } \\
\text { Corni; Cornus officinalis Siebold \& } \\
\text { Zucc.), Shan-Yao (Rhizoma Dioscoreae; } \\
\text { Dioscorea opposita Thunb.), Fu-Ling } \\
\text { (Poria; Wolfiporia extensa (Peck) Ginns), } \\
\text { Mu-Dan-Pi (Cortex Moutan; Moutan } \\
\text { officinalis (L.) Lindl. \& Paxton), Ze-Xie } \\
\text { (Rhizoma Alismatis; Alisma plantago- } \\
\text { aquatica L.) }\end{array}$ & 688 & 33.3 & 3475 & 4662 & 4.4 & 8.1 \\
\hline
\end{tabular}

(Continued) 


\begin{tabular}{|c|c|c|c|c|c|c|c|c|c|c|}
\hline Formulas & $\begin{array}{l}\text { Pin-yin } \\
\text { name } \\
\text { (shorten } \\
\text { name) }\end{array}$ & $\begin{array}{l}\text { Chinese } \\
\text { name }\end{array}$ & $\begin{array}{l}\text { Number of } \\
\text { herbs }\end{array}$ & $\begin{array}{l}\text { Composition (Pin-yin name (latin name; } \\
\text { botanical plant name)) }\end{array}$ & $\begin{array}{c}\text { User } \\
\text { number }\end{array}$ & $\begin{array}{c}\text { Percentage } \\
\text { of user } \\
\text { number }\end{array}$ & $\begin{array}{l}\text { Frequency } \\
\text { of } \\
\text { prescription }\end{array}$ & $\begin{array}{l}\text { Person- } \\
\text { year }\end{array}$ & $\begin{array}{l}\text { Average } \\
\text { drug dose } \\
\text { per day } \\
\text { (g) }\end{array}$ & $\begin{array}{l}\text { Average } \\
\text { duration for } \\
\text { prescription } \\
\text { (days) }\end{array}$ \\
\hline \multirow{12}{*}{$\begin{array}{l}\text { Single } \\
\text { herbs }^{\text {a }}\end{array}$} & $\begin{array}{l}\text { Suan-Zao- } \\
\text { Ren-Tang } \\
\text { (SZRT) }\end{array}$ & $\begin{array}{l}\text { 酸呆仁 } \\
\text { 湯 }\end{array}$ & 5 & $\begin{array}{l}\text { Suan-Zao-Ren (Semen Zizyphi Spinosae; } \\
\text { Ziziphus jujuba Mill.), Fu-Ling (Poria; } \\
\text { Wolfiporia extensa (Peck) Ginns), Zhi-Mu } \\
\text { (Rhizoma Anemarrhenae; Anemarrhena } \\
\text { asphodeloides Bunge.), Gao-Ben } \\
\text { (Rhizoma Ligustici; Ligusticum sinense } \\
\text { Oliv.), Gan-Cao (Radix Glycyrrhizae } \\
\text { Preparata; Glycyrrhiza uralensis Fisch.) }\end{array}$ & 638 & 30.9 & 3486 & 4204.3 & 3.9 & 7.7 \\
\hline & & & & & 2031 & 98.2 & 77320 & 12617 & 4 & 7.3 \\
\hline & $\begin{array}{c}\text { Yan-Hu- } \\
\text { Suo (YHS) }\end{array}$ & 延胡索 & 1 & $\begin{array}{c}\text { Yan-Hu-Suo (Rhizoma Corydalis; } \\
\text { Corydalis yanhusuo (Y.H.Chou \& Chun } \\
\text { C.Hsu) W.T.Wang ex Z.Y.Su \& C.Y.Wu) }\end{array}$ & 994 & 48.1 & 5999 & 6572.8 & 1.1 & 6.9 \\
\hline & $\begin{array}{l}\text { Ge-Gen } \\
\text { (GG) }\end{array}$ & 葛根 & 1 & $\begin{array}{c}\text { Ge-Gen (Radix Puerariae; Pueraria } \\
\text { lobata (Willd.) Ohwi) }\end{array}$ & 871 & 42.1 & 5016 & 5737.6 & 1.3 & 7.3 \\
\hline & $\begin{array}{l}\text { Huang-Qin } \\
\text { (HQin) }\end{array}$ & 黄芩 & 1 & $\begin{array}{l}\text { Huang-Qin (Radix Scutellariae; } \\
\text { Scutellaria baicalensis Georgi) }\end{array}$ & 830 & 40.1 & 4604 & 5475.6 & 1.1 & 7 \\
\hline & $\begin{array}{l}\text { Dan-Shen } \\
\text { (DS) }\end{array}$ & 丹參 & 1 & $\begin{array}{c}\text { Dan-Shen (Radix Salviae Miltiorrhizae; } \\
\text { Salvia miltiorrhiza Bunge) }\end{array}$ & 814 & 39.4 & 5297 & 5270.5 & 1.2 & 8.9 \\
\hline & $\begin{array}{l}\text { Jie-Geng } \\
\text { (JG) }\end{array}$ & 桔梗 & 1 & $\begin{array}{c}\text { Jie-Geng (Radix Platycodi; Platycodon } \\
\text { grandiflorus (Jacq.) A.DC.) }\end{array}$ & 792 & 38.3 & 4359 & 5135.2 & 1 & 6.3 \\
\hline & $\begin{array}{l}\text { Bei-Mu } \\
\text { (BM) }\end{array}$ & 貝母 & 1 & $\begin{array}{c}\text { Bei-Mu (Bulbus Fritillariae Cirrhosae; } \\
\text { Fritillaria cirrhosa D.Don) }\end{array}$ & 765 & 37 & 4900 & 5038 & 1.1 & 6.7 \\
\hline & $\begin{array}{l}\text { Tian-Hua- } \\
\text { Fen (THF) }\end{array}$ & 天花粉 & 1 & $\begin{array}{l}\text { Tian-Hua-Fen (Radix Trichosanthis; } \\
\text { Trichosanthes kirilowii Maxim.) }\end{array}$ & 746 & 36.1 & 4173 & 4928.7 & 1.2 & 7.9 \\
\hline & $\begin{array}{l}\text { Niu-Xi } \\
\text { (NX) }\end{array}$ & 牛膝 & 1 & $\begin{array}{c}\text { Niu-Xi (Radix Achyranthis Bidentatae; } \\
\text { Achyranthes bidentata Blume) }\end{array}$ & 659 & 31.9 & 3182 & 4482.9 & 1.1 & 7.7 \\
\hline & $\begin{array}{l}\text { Xiang-Fu } \\
\quad(X F)\end{array}$ & 香附 & 1 & $\begin{array}{c}\text { Xiang-Fu (Rhizoma Cyperi; Cyperus } \\
\text { rotundus L.) }\end{array}$ & 657 & 31.8 & 3327 & 4347.2 & 1 & 7.2 \\
\hline & $\begin{array}{l}\text { Huang-Qi } \\
\text { (HQ) }\end{array}$ & 黃苩 & 1 & $\begin{array}{c}\text { Huang-Qi (Radix Astragali; Astragalus } \\
\text { membranaceus (Fisch.) Bunge) }\end{array}$ & 653 & 31.6 & 3219 & 4273.4 & 1.3 & 8.1 \\
\hline
\end{tabular}

*Sorted by user number. T2D, type 2 diabetes.

anformation are obtained from the websites (http://www.americandragon.com/index.htm; http://old.tcmwiki.com/; http:// www.shen-nong.com/eng/front/index.html; http://www.ipni.org/; http://www.theplantlist.org/).

possesses anti-inflammatory properties. The main active component is an oleanane-type saponin, which was shown to inhibit interleukin-1 $\beta$-induced nuclear factor- $\kappa \mathrm{B}$ activation in rat chondrocytes [64].

In cluster 3, GGT was the core CHM and the only CHM in this cluster that reduced the $\mathrm{H}_{2} \mathrm{O}_{2}$-induced phosphorylation of both p38 MAPK and p44/42 MAPKs (ERK1/2) in retina cells. GGT is a traditional Chinese medicinal formula composed of seven single herbs. There are seven pharmacologically active natural compounds, puerarin, daidzin, daidein, paeoniflorin, albiflorin, liquiritin, and liquiritigenin, detected in GGT [65]. This formula is widely used as a treatment for a common cold and migraine, as well as to improve the symptoms of gastrointestinal and respiratory disorders [66-68]. Among the seven single herbs, GG (Pueraria lobata (Willd.) Ohwi), Bai-Shao (P. lactiflora Pall.), and Gan-Cao (Glycyrrhiza uralensis Fisch.) are the three major herbs. GG (P. lobata (Willd.) Ohwi) contains an isoflavonoid glycoside with hypotensive activity, which has shown excellent clinical results for the treatment of hypertension [69], as well as puerarin, daidzin, and daidein [70]. Puerarin, the major active ingredient of GG, has been shown to exert significant protective effects against diabetic retinopathy in rats by regulating the expression of factors involved in angiogenesis [70]. As previously described, Bai-Shao (P. lactiflora Pall.) contains paeoniflorin and albiflorin $[52,53]$. Gan-Cao (G. uralensis Fisch.) contains glycyrrhizin, glycyrrhizic acid, liquiritin, and liquiritigenin [71] and exhibits antiinflammatory activities [72, 73]. Therefore, there are at least nine known pharmacologically active natural compounds, puerarin, daidzin, daidein, paeoniflorin, albiflorin, glycyrrhizin, glycyrrhizic acid, liquiritin, and liquiritigenin, in the herbal formula GGT (cluster 3). Among these nine natural compounds, treatment with glycyrrhizin and liquiritigenin (without $\mathrm{H}_{2} \mathrm{O}_{2}$ ) resulted in detectable fluorescence, suggesting that the color 
Table 4: Six most commonly used combinations for female patients with T2D

\begin{tabular}{|c|c|c|c|c|c|c|}
\hline CHM combinations & $\begin{array}{c}\text { User } \\
\text { number }\end{array}$ & $\begin{array}{c}\text { Percentage } \\
\text { of user } \\
\text { number }\end{array}$ & $\begin{array}{l}\text { Frequency } \\
\text { of } \\
\text { prescription }\end{array}$ & $\begin{array}{l}\text { Person- } \\
\text { year }\end{array}$ & $\begin{array}{c}\text { Average } \\
\text { drug dose } \\
\text { per day (g) }\end{array}$ & $\begin{array}{c}\text { Average } \\
\text { duration for } \\
\text { prescription } \\
\text { (days) }\end{array}$ \\
\hline Total & 1828 & 100 & 26977 & 11449 & 5.7 & 7.4 \\
\hline $\begin{array}{l}\text { Shu-Jing-Huo-Xue-Tang (SJHXT) and } \\
\text { Shao-Yao-Gan-Cao-Tang (SYGCT) }\end{array}$ & 271 & 14.8 & 774 & 1873 & 6.5 & 6.8 \\
\hline Jie-Geng (JG) and Bei-Mu (BM) & 270 & 14.8 & 821 & 1761 & 2.1 & 6.3 \\
\hline $\begin{array}{l}\text { Shao-Yao-Gan-Cao-Tang (SYGCT) and } \\
\text { Yan-Hu-Suo (YHS) }\end{array}$ & 237 & 13 & 640 & 1606 & 4.2 & 6.4 \\
\hline $\begin{array}{l}\text { Shu-Jing-Huo-Xue-Tang (SJHXT) and } \\
\text { Yan-Hu-Suo (YHS) }\end{array}$ & 227 & 12.4 & 648 & 1489 & 5.2 & 7 \\
\hline $\begin{array}{l}\text { Jia-Wei-Xiao-Yao-San (JWXYS) and } \\
\text { Suan-Zao-Ren-Tang (SZRT) }\end{array}$ & 221 & 12.1 & 702 & 1490 & 7.5 & 8.1 \\
\hline $\begin{array}{l}\text { Jia-Wei-Xiao-Yao-San (JWXYS) and } \\
\text { Dan-Shen (DS) }\end{array}$ & 212 & 11.6 & 827 & 1478 & 5.7 & 10.4 \\
\hline
\end{tabular}

*Sorted by user number.

anformation are obtained from the websites (http://www.americandragon.com/index.htm; http://old.tcmwiki.com/; http:// www.shen-nong.com/eng/front/index.html; http://www.ipni.org/; http://www.theplantlist.org/).

CHM, Chinese herbal medicine; T2D, type 2 diabetes.

of glycyrrhizin and liquiritigenin may interfere with the detection of intracellular ROS production by flow cytometry. Thus, these two natural compounds are not suitable for the detection of the protective effect against $\mathrm{H}_{2} \mathrm{O}_{2}$-induced ROS using the flow cytometry method. We, therefore, investigated the effects of the rest of the natural compounds. The results suggested that these natural compounds from GGT reduced the cellular ROS levels compared with those in $\mathrm{H}_{2} \mathrm{O}_{2}$-treated cells.

In cluster 4, HQin was the core CHM and the only CHM that reduced the $\mathrm{H}_{2} \mathrm{O}_{2}$-induced phosphorylation of both p38 MAPK and p44/42 MAPKs (ERK1/2). Since treatment with HQin alone (without $\mathrm{H}_{2} \mathrm{O}_{2}$ ) resulted in detectable fluorescence, this single herb and its relevant natural compounds are not suitable for the detection of intracellular ROS by flow cytometry. HQin is composed of Scutellaria baicalensis Georgi and affects glucosestimulated insulin secretion and $\beta$-cell proliferation. It also induces anti-apoptotic effects on vascular endothelial cells, resulting in the prevention of diabetes-associated microvascular complications $[74,75]$. In addition, HQin attenuates oxidative stress and inflammation [76, 77]. Our in vitro experiments showed that $\mathrm{HQin}$ reduced the $\mathrm{H}_{2} \mathrm{O}_{2}$ induced phosphorylation of both p38 MAPK and p44/42 MAPKs (ERK1/2) in ARPE-19 retina cells.

To our knowledge, this is the first population-based pharmacoepidemiological study focused on the effect of CHM use on the occurrence of diabetic retinopathy. By using the Taiwan NHIRD, we were able to investigate the demographic characteristics, cumulative probability of retinopathy, CHM prescription patterns, and the networks of T2D patients. We also evaluated the CHM effects on human retina cells in vitro. This investigation may provide the scientific basis or therapeutic directions for the prevention of diabetic retinopathy.

In conclusion, diabetic retinopathy is one of the microvascular complications of T2D and the leading cause of acquired blindness. Our results suggest that adjunctive CHM treatment may reduce the occurrence of diabetic retinopathy owing to antioxidant activities of the herbs.

\section{MATERIALS AND METHODS}

\section{Study population}

This study was a population-based, case-control study. The study subjects were selected from the Longitudinal Health Insurance Database (LHID2000 and LHID2005). Individuals with diabetes (ICD-9-CM: 250) were identified between the years 2000 and 2009. Patients with type 1 diabetes or diabetic retinopathy that occurred within 1 year of T2D diagnosis were excluded (Figure 1). After applying these criteria, 23,701 study subjects were included in the study cohort. Subjects who took CHM products for more than 28 days within the first year of T2D were defined as CHM users ( $n=7,213$; Figure 1$)$. These $\mathrm{CHM}$ users continued to use CHM products during this study period (between the index date and study endpoint). 
The index date was defined as the date by which 28 days of CHM treatment had been achieved. Subjects with no record of CHM treatment were defined as CHM non-users during this study period ( $n=16,488$; Figure 1$)$. The date of death, withdrawal from the NHI program, or followup termination (December 31, 2012) was considered the study endpoint. The propensity score matching method was used to match the CHM users and non-users at a 1:1 ratio. After matching these two groups for age and gender, CHM users and non-users were selected (Figure 1 and Table 1). All data for each individual were coded, and therefore we could not obtain their informed consent. This study was evaluated and approved by the Institutional Review Board of the China Medical University Hospital.

\section{Chinese herbal medicines}

Single-herb preparations are obtained from plants, animals, or mineral materials. These are mixed to create a formulation. Herbal formulations contain a combination of 2-17 herbs (Table 3), which are prepared by experienced TCM doctors. These formulations have been used since ancient China. The single herbs and herbal formulations from this study were produced by good manufacturing practice-certified TCM manufacturers based in Taiwan. These manufacturers included Sun Ten Pharmaceutical Co., Ltd., Shang Chang Pharmaceutical Co., Ltd., Chuang Song Zong Pharmaceutical Co., Ltd., KO DA Pharmaceutical Co., Ltd., and Kaiser Pharmaceutical Co., Ltd. For each herbal product, the number of users, percentage of users, frequency of prescription, personyears, average drug dose per day, and average duration of prescription were collected and calculated from the day of T2D diagnosis through the study endpoint (Table 3 ).

\section{Cell culture and CHM treatment}

Human retinal pigmented epithelium cells (ARPE19 cell line; American Type Culture Collection CRL2302) were maintained in Dulbecco's modified Eagle's medium supplemented with $10 \%$ fetal bovine serum, 100 $\mathrm{U} / \mathrm{mL}$ penicillin, $100 \mu \mathrm{g} / \mathrm{mL}$ streptomycin, and $2 \mathrm{mM}$ L-glutamine (Gibco, Thermo Fisher Scientific, Waltham, MA, USA). A human insulin solution (catalog number I9278) and hydrogen peroxide solution (catalog number 18304) were purchased from Sigma-Aldrich (St. Louis, MO, USA). ARPE-19 cells were treated with insulin (200 nM; Supplementary Figures 2 and 3), herbal formulas (1 mg/mL), and single herbs $(1 \mathrm{mg} / \mathrm{mL})$ for $4 \mathrm{~h}$ (Table 3 and Figures 3-6). The insulin- and CHM-treated ARPE19 cells were then incubated with the $\mathrm{H}_{2} \mathrm{O}_{2}$ solution (300 $\mu \mathrm{M}$; Supplementary Figures 2 and 3) for $30 \mathrm{~min}$. The treated cells were lysed in RIPA buffer (catalog number 89900, Thermo Fisher Scientific, Rockford, IL, USA) with protease inhibitors (complete EDTA-free protease inhibitors, catalog number 11873580001, Sigma-Aldrich) and a phosphatase inhibitor (catalog number 88667, Thermo Fisher Scientific), then subjected to $12 \%$ sodium dodecyl sulfate polyacrylamide gel electrophoresis, and transferred to polyvinylidene difluoride membranes (Millipore, Billerica, MA, USA). To perform Western blot analysis, the membranes were incubated with primary antibodies overnight at $4{ }^{\circ} \mathrm{C}$. The primary antibodies included anti-phospho-p38 MAPK (Thr180/Tyr182; D3F9, catalog number 4511), anti-p38 MAPK (catalog number 9212), anti-phospho-p44/42 MAPK (ERK1/2) (Thr202/Tyr204)(catalog number 4370), and anti-p44/42 MAPK (ERK1/2) (catalog number 4695) antibodies from Cell Signaling Technology, Inc. (Beverly, MA, USA) and an anti-glyceraldehyde 3-phosphate dehydrogenase (GAPDH) antibody (catalog number 10494-1-AP) from Proteintech Group, Inc. (Rosemont, IL, USA). The membranes were then incubated with alkaline phosphatase-conjugated secondary antibodies (Sigma-Aldrich). Signals were visualized using a chemiluminescence kit (Chemicon), following the manufacturer's protocol.

In addition, detection of intracellular ROS production was performed using flow cytometry (Supplementary Figures 4-7). ARPE-19 retina cells were pretreated with insulin, CHMs, or natural compounds for $18 \mathrm{~h}$. The treated cells were then stained with $5 \mu \mathrm{M}$ $2^{\prime}, 7^{\prime}$-dichlorofluorescin diacetate (DCFH-DA) for 30 min, followed by incubation with $\mathrm{H}_{2} \mathrm{O}_{2}(300 \mu \mathrm{M})$ for 5 min to induce the intracellular ROS generation. DCFHDA fluorescence intensities were then measured by flow cytometry at an excitation wavelength of $488 \mathrm{~nm}$ and an emission wavelength of $535 \mathrm{~nm}$ (FACSCanto ${ }^{\text {TM }}$ flow cytometry system; BD Biosciences, San Jose, CA, USA). The relative fluorescence intensity of ROS is expressed as fluorescence intensity of treated cells versus that of the untreated control.

\section{Statistical analysis}

Demographic data, including age, gender, comorbidities, medications, income, and urbanization levels were analyzed for both CHM users and non-users. Each categorical variable is presented as the number or percentage of patients, and chi-squared tests were performed (Table 1). Comorbidity was also considered as a study covariate based on the disease history prior to T2D diagnosis (Table 1). We identified the following comorbidities: chronic obstructive pulmonary disease (ICD-9-CM: 490-496), cerebrovascular disease (ICD-9CM: 430-438), renal disease (ICD-9-CM: 582, 583-583.7, 585, 586, and 588), hyperlipidemia (ICD-9-CM: 272), obesity (ICD-9-CM: 278 and 278.01), alcohol-related illness (ICD-9-CM: 303, 305, 305.01, 305.02, 305.03, and V11.3), hypertension (ICD-9-CM: 401-405), and myocardial infarction (ICD-9-CM: 410 and 412) (Table 1). Urbanization levels in Taiwan are divided into five strata, 
according to Taiwan National Health Research Institutes publications, with level 1 referring to the most urbanized communities and level 5 referring to the least urbanized communities. The Cox's proportional hazards model was applied to evaluate the effect of CHM on the occurrence of diabetic retinopathy among T2D patients (Table 2). The Kaplan-Meier method and log-rank test were employed to estimate the cumulative probability of diabetic retinopathy between CHM users and non-users (Figure 2). The top 10 most commonly used herbal formulations and single herbs are shown according to the number of users for each CHM (Table 3). The top six most commonly used CHM combinations are shown according to the number of users for each combination (Table 4). The social network analysis of SAS Visual Analytics was applied to explore the CHM network and core treatments for female patients with T2D from the Taiwan NHIRD (http://blogs.sas.com/ content/sascom/2014/02/19/exploring-social-networkswith-sas-visual-analytics/; Table 4 and Figure 7). All $P$ values of less than 0.05 were considered significant. Data manipulation and statistical analyses were performed using the Statistical Analysis System software (version 9.3; SAS Institute, Cary, NC, USA).

\section{Abbreviations}

ARPE-19 cells: Adult Retinal Pigment Epithelial cell line-19 cells; T2D: type 2 diabetes; CHM: Chinese herbal medicine; $\mathrm{CI}$ : confidence interval.

\section{ACKNOWLEDGMENTS}

This study was supported by grants from China Medical University (CMU102-PH-01), the China Medical University Hospital (DMR-106-155), the Ministry of Science and Technology, Republic of China (Taiwan) (MOST 103-2320-B-039-006-MY3 and MOST 105-2314-B-039-037-MY3), and China Medical University, under the Aim for Top University Plan of the Ministry of Education, Taiwan. The authors wish to thank the Department of Internal Medicine, China Medical University Hospital, for administrative assistance. We also thank Drs. Kuan-Teh Jeang and Willy W. L. Hong for technical help and suggestions.

\section{CONFLICTS OF INTEREST}

The authors declare that no conflicts of interest existed.

\section{REFERENCES}

1. American Diabetes Association. Diagnosis and classification of diabetes mellitus. Diabetes Care. 2009; 32:S62-67.
2. Stumvoll M, Goldstein BJ, van Haeften TW. Type 2 diabetes: principles of pathogenesis and therapy. Lancet. 2005; 365:1333-1346.

3. Kahn SE, Hull RL, Utzschneider KM. Mechanisms linking obesity to insulin resistance and type 2 diabetes. Nature. 2006; 444:840-846.

4. Haring R, Wallaschofski H, Nauck M, Felix SB, Schmidt CO, Dorr M, Sauer S, Wilmking G, Volzke H. Total and cardiovascular disease mortality predicted by metabolic syndrome is inferior relative to its components. Exp Clin Endocrinol Diabetes. 2010; 118:685-691.

5. Zhang X, Zhao J, Zhao T, Liu H. Effects of intensive glycemic control in ocular complications in patients with type 2 diabetes: a meta-analysis of randomized clinical trials. Endocrine. 2015; 49:78-89.

6. Lopes de Faria JB, Silva KC, Lopes de Faria JM. The contribution of hypertension to diabetic nephropathy and retinopathy: the role of inflammation and oxidative stress. Hypertens Res. 2011; 34:413-422.

7. Sharma S, Saxena S, Srivastav K, Shukla RK, Mishra N, Meyer CH, Kruzliak P, Khanna VK. Nitric oxide and oxidative stress is associated with severity of diabetic retinopathy and retinal structural alterations. Clin Experiment Ophthalmol. 2015; 43:429-436.

8. Kowluru RA, Chan PS. Oxidative stress and diabetic retinopathy. Exp Diabetes Res. 2007; 2007:43603.

9. Du Y, Miller CM, Kern TS. Hyperglycemia increases mitochondrial superoxide in retina and retinal cells. Free Radic Biol Med. 2003; 35:1491-1499.

10. Kowluru RA. Effect of reinstitution of good glycemic control on retinal oxidative stress and nitrative stress in diabetic rats. Diabetes. 2003; 52:818-823.

11. Li S, Culver B, Ren J. Benefit and risk of exercise on myocardial function in diabetes. Pharmacol Res. 2003; 48:127-132.

12. Rao AD, Kuhadiya N, Reynolds K, Fonseca VA. Is the combination of sulfonylureas and metformin associated with an increased risk of cardiovascular disease or allcause mortality?: a meta-analysis of observational studies. Diabetes Care. 2008; 31:1672-1678.

13. Roumie CL, Hung AM, Greevy RA, Grijalva CG, Liu X, Murff HJ, Elasy TA, Griffin MR. Comparative effectiveness of sulfonylurea and metformin monotherapy on cardiovascular events in type 2 diabetes mellitus: a cohort study. Ann Intern Med. 2012; 157:601-610.

14. Loke YK, Singh S, Furberg CD. Long-term use of thiazolidinediones and fractures in type 2 diabetes: a metaanalysis. CMAJ. 2009; 180:32-39.

15. Lincoff AM, Wolski K, Nicholls SJ, Nissen SE. Pioglitazone and risk of cardiovascular events in patients with type 2 diabetes mellitus: a meta-analysis of randomized trials. JAMA. 2007; 298:1180-1188.

16. Singh S, Loke YK, Furberg CD. Long-term use of thiazolidinediones and the associated risk of pneumonia 
or lower respiratory tract infection: systematic review and meta-analysis. Thorax. 2011; 66:383-388.

17. Turner RM, Kwok CS, Chen-Turner C, Maduakor CA, Singh S, Loke YK. Thiazolidinediones and associated risk of bladder cancer: a systematic review and meta-analysis. Br J Clin Pharmacol. 2014; 78:258-273.

18. Lee YC, Huang YT, Tsai YW, Huang SM, Kuo KN, McKee M, Nolte E. The impact of universal National Health Insurance on population health: the experience of Taiwan. BMC Health Serv Res. 2010; 10:225.

19. Chen FP, Chen TJ, Kung YY, Chen YC, Chou LF, Chen FJ, Hwang SJ. Use frequency of traditional Chinese medicine in Taiwan. BMC Health Serv Res. 2007; 7:26.

20. Huang TP, Liu PH, Lien AS, Yang SL, Chang HH, Yen HR. Characteristics of traditional Chinese medicine use in children with asthma: a nationwide population-based study. Allergy. 2013; 68:1610-1613.

21. Lai JN, Wu CT, Wang JD. Prescription pattern of Chinese herbal products for breast cancer in taiwan: a populationbased study. Evid Based Complement Alternat Med. 2012; 2012:891893.

22. Hsieh CF, Huang SL, Chen CL, Chen WT, Chang HC, Yang CC. Non-aristolochic acid prescribed Chinese herbal medicines and the risk of mortality in patients with chronic kidney disease: results from a population-based follow-up study. BMJ Open. 2014; 4:e004033.

23. Huang CY, Tsai YT, Lai JN, Hsu FL. Prescription pattern of chinese herbal products for diabetes mellitus in taiwan: a population-based study. Evid Based Complement Alternat Med. 2013; 2013:201329.

24. Fang RC, Tsai YT, Lai JN, Yeh CH, Wu CT. The traditional chinese medicine prescription pattern of endometriosis patients in taiwan: a population-based study. Evid Based Complement Alternat Med. 2012; 2012:591391.

25. Pan JC, Tsai YT, Lai JN, Fang RC, Yeh CH. The traditional Chinese medicine prescription pattern of patients with primary dysmenorrhea in Taiwan: a large-scale cross sectional survey. J Ethnopharmacol. 2014; 152:314-319.

26. Lin HC, Yang WC, Lee HC. Traditional Chinese medicine usage among schizophrenia patients. Complement Ther Med. 2008; 16:336-342.

27. Yu MC, Lin SK, Lai JN, Wei JC, Cheng CY. The traditional Chinese medicine prescription patterns of Sjogrens patients in Taiwan: a population-based study. J Ethnopharmacol. 2014; 155:435-442.

28. Lin YJ, Ho TJ, Yeh YC, Cheng CF, Shiao YT, Wang CB, Chien WK, Chen JH, Liu X, Tsang H, Lin TH, Liao CC, Huang SM, et al. Chinese herbal medicine treatment improves the overall survival rate of individuals with hypertension among type 2 diabetes patients and modulates In Vitro smooth muscle cell contractility. PLoS One. 2015; 10:e0145109.
29. Feng S, Song L, Liu Y, Lai F, Zuo G, He G, Chen M, Huang D. Hypoglycemic activities of commonly-used traditional Chinese herbs. Am J Chin Med. 2013; 41:849-864.

30. Chang YX, Ge AH, Donnapee S, Li J, Bai Y, Liu J, He J, Yang X, Song LJ, Zhang BL, Gao XM. The multi-targets integrated fingerprinting for screening anti-diabetic compounds from a Chinese medicine Jinqi Jiangtang Tablet. J Ethnopharmacol. 2015; 164:210-222.

31. Lian F, Li G, Chen X, Wang X, Piao C, Wang J, Hong Y, Ba Z, Wu S, Zhou X, Lang J, Liu Y, Zhang R, et al. Chinese herbal medicine Tianqi reduces progression from impaired glucose tolerance to diabetes: a double-blind, randomized, placebo-controlled, multicenter trial. J Clin Endocrinol Metab. 2014; 99:648-655.

32. Grant SJ, Bensoussan A, Chang D, Kiat H, Klupp NL, Liu JP, Li X. Chinese herbal medicines for people with impaired glucose tolerance or impaired fasting blood glucose. Cochrane Database Syst Rev. 2009; (4):CD006690.

33. Xie P, Fujii I, Zhao J, Shinohara M, Matsukura M. A novel polysaccharide compound derived from algae extracts protects retinal pigment epithelial cells from high glucoseinduced oxidative damage in vitro. Biol Pharm Bull. 2012; 35:1447-1453.

34. Wankun X, Wenzhen Y, Min Z, Weiyan Z, Huan C, Wei D, Lvzhen H, Xu Y, Xiaoxin L. Protective effect of paeoniflorin against oxidative stress in human retinal pigment epithelium in vitro. Mol Vis. 2011; 17:3512-3522.

35. Hanneken A, Lin FF, Johnson J, Maher P. Flavonoids protect human retinal pigment epithelial cells from oxidative-stress-induced death. Invest Ophthalmol Vis Sci. 2006; 47:3164-3177.

36. Qu Y, Gan HQ, Mei QB, Liu L. Study on the effect of JiaWei-Xiao-Yao-San decoction on patients with functional dyspepsia. Phytother Res. 2010; 24:245-248.

37. Chao $\mathrm{TH}, \mathrm{Fu} \mathrm{PK}$, Chang $\mathrm{CH}$, Chang SN, Chiahung Mao F, Lin CH. Prescription patterns of Chinese herbal products for post-surgery colon cancer patients in Taiwan. $\mathrm{J}$ Ethnopharmacol. 2014; 155:702-708.

38. Wang BR, Chang YL, Chen TJ, Chiu JH, Wu JC, Wu MS, Chou CL, Chou YC. Coprescription of Chinese herbal medicine and Western medication among female patients with breast cancer in Taiwan: analysis of national insurance claims. Patient Prefer Adherence. 2014; 8:671-682.

39. Chen LC, Tsao YT, Yen KY, Chen YF, Chou MH, Lin MF. A pilot study comparing the clinical effects of Jia-Wey Shiau-Yau San, a traditional Chinese herbal prescription, and a continuous combined hormone replacement therapy in postmenopausal women with climacteric symptoms. Maturitas. 2003; 44:55-62.

40. Chien SC, Chang WC, Lin PH, Chang WP, Hsu SC, Chang JC, Wu YC, Pei JK, Lin CH. A Chinese herbal medicine, jia-wei-xiao-yao-san, prevents dimethylnitrosamineinduced hepatic fibrosis in rats. ScientificWorldJournal. 2014; 2014:217525. 
41. Ma YC, Lin CC, Li CI, Chiang JH, Li TC, Lin JG. Traditional Chinese medicine therapy improves the survival of systemic lupus erythematosus patients. Semin Arthritis Rheum. 2016; 45:596-603.

42. Lin PH, Lin SK, Hsu RJ, Cheng KC, Liu JM. The use and the prescription pattern of traditional Chinese medicine among urolithiasis patients in Taiwan: a population-based study. J Altern Complement Med. 2016; 22:88-95.

43. Tsai DS, Huang MH, Chang YS, Li TC, Peng WH. The use of Chinese herbal medicines associated with reduced mortality in chronic hepatitis B patients receiving lamivudine treatment. J Ethnopharmacol. 2015; 174:161-167.

44. Chen YL, Lee CY, Huang KH, Kuan YH, Chen M. Prescription patterns of Chinese herbal products for patients with sleep disorder and major depressive disorder in Taiwan. J Ethnopharmacol. 2015; 171:307-316.

45. Liao $\mathrm{YH}$, Lin $\mathrm{CC}$, Lai $\mathrm{HC}$, Chiang JH, Lin JG, Li TC. Adjunctive traditional Chinese medicine therapy improves survival of liver cancer patients. Liver Int. 2015; 35:2595-2602.

46. Lin SK, Tsai YT, Lai JN, Wu CT. Demographic and medication characteristics of traditional Chinese medicine users among dementia patients in Taiwan: a nationwide database study. J Ethnopharmacol. 2015; 161:108-115.

47. Tsai YT, Lai JN, Wu CT. The use of Chinese herbal products and its influence on tamoxifen induced endometrial cancer risk among female breast cancer patients: a populationbased study. J Ethnopharmacol. 2014; 155:1256-1262.

48. Chao TH, Fu PK, Chang CH, Chang SN, Chiahung Mao F, Lin CH, Evidence-based Chinese Medicine Research Group. Prescription patterns of Chinese herbal products for post-surgery colon cancer patients in Taiwan. J Ethnopharmacol. 2014; 155:702-708.

49. Li ZY, Zhang ZZ, Du GH, Qin XM. Comparative analysis of Danggui and European Danggui using nuclear magnetic resonance-based metabolic fingerprinting. J Pharm Biomed Anal. 2015; 103:44-51.

50. Sung JH, Gim SA, Koh PO. Ferulic acid attenuates the cerebral ischemic injury-induced decrease in peroxiredoxin-2 and thioredoxin expression. Neurosci Lett. 2014; 566:88-92.

51. Li SY, Yu Y, Li SP. Identification of antioxidants in essential oil of radix Angelicae sinensis using HPLC coupled with DAD-MS and ABTS-based assay. J Agric Food Chem. 2007; 55:3358-3362.

52. Wang QS, Gao T, Cui YL, Gao LN, Jiang HL. Comparative studies of paeoniflorin and albiflorin from Paeonia lactiflora on anti-inflammatory activities. Pharm Biol. 2014; 52:1189-1195.

53. Xu CH, Wang P, Wang Y, Yang Y, Li DH, Li HF, Sun SQ, Wu XZ. Pharmacokinetic comparisons of two different combinations of Shaoyao-Gancao Decoction in rats: competing mechanisms between paeoniflorin and glycyrrhetinic acid. J Ethnopharmacol. 2013; 149:443-452.

54. Dong H, Li R, Yu C, Xu T, Zhang X, Dong M. Paeoniflorin inhibition of 6-hydroxydopamine-induced apoptosis in PC12 cells via suppressing reactive oxygen speciesmediated PKCdelta/NF-kappaB pathway. Neuroscience. 2015; 285:70-80.

55. Zhu YZ, Huang SH, Tan BK, Sun J, Whiteman M, Zhu YC. Antioxidants in Chinese herbal medicines: a biochemical perspective. Nat Prod Rep. 2004; 21:478-489.

56. Su CY, Ming QL, Rahman K, Han T, Qin LP. Salvia miltiorrhiza: traditional medicinal uses, chemistry, and pharmacology. Chin J Nat Med. 2015; 13:163-182.

57. Pirzada AM, Ali HH, Naeem M, Latif M, Bukhari AH, Tanveer A. Cyperus rotundus L.: traditional uses, phytochemistry, and pharmacological activities. J Ethnopharmacol. 2015; 174:540-560.

58. Thomas D, Govindhan S, Baiju EC, Padmavathi G, Kunnumakkara AB, Padikkala J. Cyperus rotundus L. prevents non-steroidal anti-inflammatory drug-induced gastric mucosal damage by inhibiting oxidative stress. J Basic Clin Physiol Pharmacol. 2015; 26:485-490.

59. Liao HH, Yeh CC, Lin CC, Chen BC, Yeh MH, Chang KM, Sun MF, Yen HR. Prescription patterns of Chinese herbal products for patients with fractures in Taiwan: a nationwide population-based study. J Ethnopharmacol. 2015; 173:11-19.

60. Lin YH, Chen KK, Chiu JH. Coprescription of Chinese herbal medicine and western medications among prostate cancer patients: a population-based study in Taiwan. Evid Based Complement Alternat Med. 2012; 2012:147015.

61. Chou CT, Wu WL, Chang ML, Chang DM. Efficacy and possible mechanisms of the Chinese herbs suching-huohsuei-tang in the treatment of adjuvant-induced arthritis in rats. Am J Chin Med. 1993; 21:159-170.

62. Shu H, Arita H, Hayashida M, Zhang L, An K, Huang W, Hanaoka K. Anti-hypersensitivity effects of Shu-jing-huoxue-tang, a Chinese herbal medicine, in CCI-neuropathic rats. J Ethnopharmacol. 2010; 131:464-470.

63. Kanai S, Taniguchi N, Higashino H. Study of sokeikakketu-to (shu-jing-huo-xue-tang) in adjuvant arthritis rats. Am J Chin Med. 2003; 31:879-884.

64. Xu XX, Zhang XH, Diao Y, Huang YX. Achyranthes bidentate saponins protect rat articular chondrocytes against interleukin-1beta-induced inflammation and apoptosis in vitro. Kaohsiung J Med Sci. 2017; 33:62-68.

65. Yan Y, Chai CZ, Wang DW, Wu J, Xiao HH, Huo LX, Zhu DN, Yu BY. Simultaneous determination of puerarin, daidzin, daidzein, paeoniflorin, albiflorin, liquiritin and liquiritigenin in rat plasma and its application to a pharmacokinetic study of Ge-Gen Decoction by a liquid chromatography-electrospray ionization-tandem mass spectrometry. J Pharm Biomed Anal. 2014; 95:76-84. 
66. Lee S, Gim H, Shim JH, Jung Kim H, Lee JR, Kim SC, Kwon YK, Ha KT, So I, Kim BJ. The traditional herbal medicine, Ge-Gen-Tang, inhibits pacemaker potentials by nitric oxide/cGMP dependent ATP-sensitive $\mathrm{K}(+)$ channels in cultured interstitial cells of Cajal from mouse small intestine. J Ethnopharmacol. 2015; 170:201-209.

67. Chang YY, Tsai YT, Lai JN, Yeh CH, Lin SK. The traditional Chinese medicine prescription patterns for migraine patients in Taiwan: a population-based study. J Ethnopharmacol. 2014; 151:1209-1217.

68. Chang JS, Wang KC, Shieh DE, Hsu FF, Chiang LC. Ge-Gen-Tang has anti-viral activity against human respiratory syncytial virus in human respiratory tract cell lines. J Ethnopharmacol. 2012; 139:305-310.

69. Qicheng F. Some current study and research approaches relating to the use of plants in the traditional Chinese medicine. J Ethnopharmacol. 1980; 2:57-63.

70. Teng Y, Cui H, Yang M, Song H, Zhang Q, Su Y, Zheng J. Protective effect of puerarin on diabetic retinopathy in rats. Mol Biol Rep. 2009; 36:1129-1133.

71. Zhou B, Zhang J, Wu S, Zhuo Q, Gao W, Hao J, Man S. The influence of compatibility of processed radix Aconiti Kusnezoffii on the pharmacokinetic of four components in Glycyrrhiza uralensis Fisch. J Ethnopharmacol. 2015; 169:1-7.

72. Yang R, Yuan BC, Ma YS, Zhou S, Liu Y. The antiinflammatory activity of licorice, a widely used Chinese herb. Pharm Biol. 2017; 55:5-18.
73. Yu JY, Ha JY, Kim KM, Jung YS, Jung JC, Oh S. Anti-inflammatory activities of licorice extract and its active compounds, glycyrrhizic acid, liquiritin and liquiritigenin, in BV2 cells and mice liver. Molecules. 2015; 20:13041-13054.

74. Suh KS, Nam YH, Ahn YM, Kim NJ, Park CY, Koh G, Oh S, Woo JT, Kim SW, Kim JW, Kim YS. Effect of Scutellariae radix extract on the high glucose-induced apoptosis in cultured vascular endothelial cells. Biol Pharm Bull. 2003; 26:1629-1632.

75. Park SM, Hong SM, Sung SR, Lee JE, Kwon DY. Extracts of Rehmanniae radix, Ginseng radix and Scutellariae radix improve glucose-stimulated insulin secretion and beta-cell proliferation through IRS2 induction. Genes Nutr. 2008; 2:347-351.

76. Jin Y, Yang J, Lin L, Lin Y, Zheng C. The attenuation of Scutellariae radix extract on oxidative stress for colon injury in lipopolysaccharide-induced RAW264.7 Cell and 2,4,6-trinitrobenzene sulfonic acid-induced ulcerative colitis rats. Pharmacogn Mag. 2016; 12:153-159.

77. Shin YO, Park CH, Lee GH, Yokozawa T, Roh SS, Rhee MH. Heat-processed Scutellariae radix enhances antiinflammatory effect against lipopolysaccharide-induced acute lung injury in mice via NF- kappa B signaling. Evid Based Complement Alternat Med. 2015; 2015:456846. 